\section{Pacific Northwest}

National Laboratory

Operated by Battelle for the

U.S. Department of Energy

\title{
Batch Reactions of a Soda-Lime Silicate Glass (Report for G Plus Project for Libbey Inc.)
}

Dong-Sang Kim

Josef Matyáš

August 2002

Prepared for the U.S. Department of Energy

under Contract DE-AC06-76RL01830

Pacific Northwest National Laboratory

Richland, Washington 99352 


\title{
DISCLAIMER
}

This report was prepared as an account of work sponsored by an agency of the United States Government. Neither the United States Government nor any agency thereof, nor Battelle Memorial Institute, nor any of their employees, makes any warranty, express or implied, or assumes any legal liability or responsibility for the accuracy, completeness, or usefulness of any information, apparatus, product, or process disclosed, or represents that its use would not infringe privately owned rights. Reference herein to any specific commercial product, process, or service by trade name, trademark, manufacturer, or otherwise does not necessarily constitute or imply its endorsement, recommendation, or favoring by the United States Government or any agency thereof, or Battelle Memorial Institute. The views and opinions of authors expressed herein do not necessarily state or reflect those of the United States Government or any agency thereof.

\author{
PACIFIC NORTHWEST NATIONAL LABORATORY \\ operated by \\ BATTELLE \\ for the \\ UNITED STATES DEPARTMENT OF ENERGY \\ under Contract DE-ACO6-76RLO183O
}

Printed in the United States of America

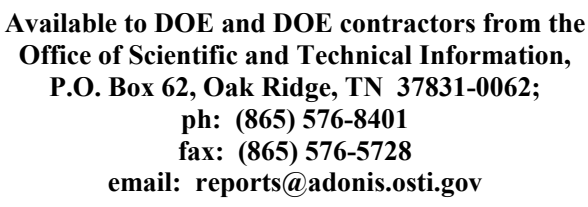

Available to the public from the National Technical Information Service, U.S. Department of Commerce, 5285 Port Royal Rd., Springfield, VA 22161 ph: (800) 553-6847 fax: $(703) 605-6900$

email: orders@ntis.fedworld.gov

online ordering: http://www.ntis.gov/ordering.htm

This document was printed on recycled paper. 


\section{Batch Reactions of a Soda-Lime Silicate Glass (Report for G Plus Project for Libbey Inc.)}

Dong-Sang Kim

Josef Matyáš

August 2002

Prepared for the U.S. Department of Energy under Contract DE-AC06-76RL01830

Pacific Northwest National Laboratory

Richland, Washington 99352 


\begin{abstract}
The purpose of this project is to develop the batch reaction data for a soda-lime-silicate glass needed to improve the batch part of the glass-furnace model being developed for the glass industry. Evolved gas analysis combined with batch expansion measurement and thermal analysis was successfully applied to obtain batch reaction data. The heat-capacity measurement by differential scanning calorimetry (DSC) was suggested as a promising method to derive the heat-of-fusion data inexpensively for many different technical glass batches. More tests on a variety of glass batches and parametric studies of the suggested methods are needed for validation. The experimental methods for batch reaction studies and the methodology for obtaining inexpensive heat-of-fusion data developed in this study can also be applied to various types of other technical glasses.
\end{abstract}




\section{Contents}

Abstract

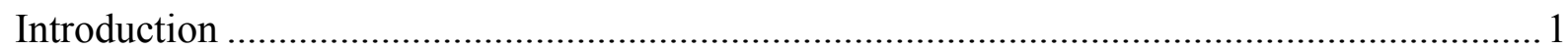

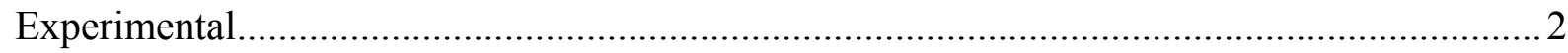

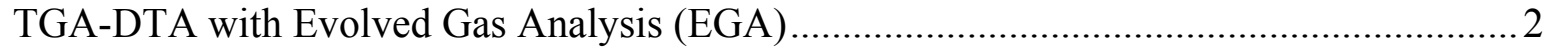

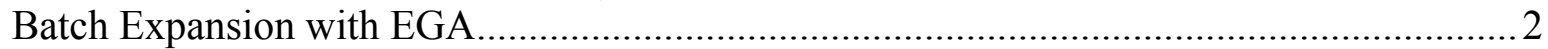

Heat Capacity and Heat of Fusion ........................................................................... 3

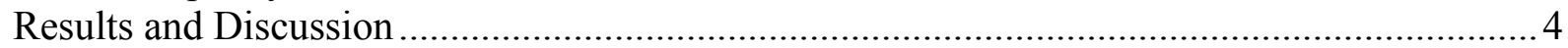

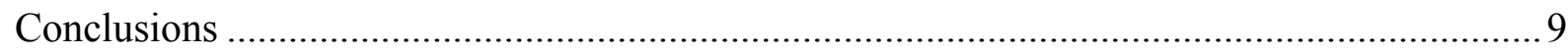

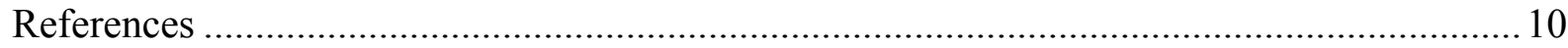

Appendix A. Discrepancy of data between two references, Madivate (1998) and

Madivate et al. (1996)................................................................................................ 12 


\section{Introduction}

The Energy Efficiency section of the Glass Industry Technology Roadmap identified "accurate validated melter models" (including batch melting, combustion, and glass flow) as a high-priority research and development (R\&D) need for improved energy efficiency. The purpose of this G Plus project is to develop the batch reaction data for a soda-lime-silicate glass needed to improve the batch part of the glass furnace model (GFM) being developed at Argonne National Laboratory (ANL) for the glass industry. Libbey Inc. is an Industrial Partner of the consortium formed for the project titled "Development and Validation of a Coupled Combustion Space/Glass Bath Simulation."

The important techniques for studying batch melting reactions have been thermogravimetric analysis and differential thermal analysis (TGA-DTA) (Wilburn and Thomasson 1958; Thomasson and Wilburn 1960; Warburton and Wilburn 1961 and 1963; Hong and Speyer 1993; Hong et al. 1993). These thermal analyses typically use a very small amount of batch sample (100 mg or less) and are ideal for detailed studies on specific parameters using rather simplified batches. Batch expansion measurement has been applied to study the foam generated from batch melting reactions using a larger size batch ( 5 to $25 \mathrm{~g}$ ) (Kim and Hrma 1990). These methods can also be integrated with other techniques, such as X-ray diffraction (XRD), to identify the reaction products (Mukerji et al. 1980; Izak et al. 2001a and 2001b), hot-stage microscope to observe the reactions as they occur (Wilburn et al. 1965), and evolved gas analysis (EGA) to determine the gas evolution rate as the reactions progress (Krämer 1980; Laimböck 1998 and 2000; Kawachi et al. 1999). This project applies the TGA-DTA and the methods for measuring batch expansion, both combined with EGA, to study melting reactions occurring in two- and three-component batches and $100 \%$ batches (referred to a normal batch containing all five major raw materials plus gypsum and carbocite) with and without glass cullet.

In addition to batch melting reactions, the batch part of the glass furnace model requires the data on heat capacity and heat of fusion on the batch materials and the glass cullet. The heat capacity of the glass was determined as a function of temperature using differential scanning calorimetry (DSC). The procedure for measuring heat capacity was also applied to the batch of raw materials to estimate the heat of fusion (or theoretical energy requirement for the fusion of glass) for the $100 \%$ batch. The heat of fusion for the $100 \%$ batch was calculated based on the method developed by Madivate (1998) and Madivate et al. (1996). The heat of fusion obtained from DSC measurement was compared with the calculated value using the model to check the applicability of the DSC method for measuring the heat of fusion as an approximation. 


\section{Experimental}

\section{TGA-DTA with Evolved Gas Analysis (EGA)}

A simultaneous TGA and DTA analysis was performed using TA Instruments SDT 2960 Simultaneous DTA-TGA. Approximately 60-mg samples were heated at a constant heating rate of $5^{\circ} \mathrm{C} / \mathrm{min}$ from room temperature to $1450^{\circ} \mathrm{C}$. The gases evolved from the batch materials and carried in a $65 \mathrm{ml} / \mathrm{min}$ stream of pure He were analyzed quantitatively by gas chromatography/mass spectrometry (GC/MS) using Hewlett Packard 5890A GC and 5971A MS. Eight different batches used in this study are described below:

Batch \#1 - 100\% batch (normal batch with five major raw materials with gypsum) (60 mg) (Carbocite was not used because the quantity was too small, $0.014 \mathrm{mg}$ )

Batch \#2 - Two parts sand (40 mg) and one part soda ash $(20 \mathrm{mg})$

Batch \#3 - Two parts sand (40 mg) and one part limestone (20 mg)

Batch \#4 - Two parts feldspar (40 mg) and one part soda ash (20 mg)

Batch \#5 - Two parts feldspar (40 mg) and one part limestone (20 mg)

Batch \#6 - Two parts sand (30 mg), one part soda ash (15 mg), and one part limestone (15 mg)

Batch \#7 - Two parts feldspar (30 mg), one part soda ash (15 mg), and one part limestone (15 mg)

Batch \#8 - Two parts sand (30 mg), one part soda ash (15 mg), and one part burnt lime (15 mg)

\section{Batch Expansion with EGA}

The batch materials with and without glass cullet contained in a tall quartz crucible were heated at $5^{\circ} \mathrm{C} / \mathrm{min}$ from 80 to $1450^{\circ} \mathrm{C}$ in a special furnace (quartz-crucible furnace) equipped with a quartz-viewing window. The batch changes as a function of time are recorded on video, and then the change of batch height is measured as a function of temperature. The following three batches were tested in this study. The total amount of batch used was the amount that gives $15 \mathrm{~g}$ of glass. The gases evolved from the batch materials and carried in a $65 \mathrm{ml} / \mathrm{min}$ stream of pure He were analyzed quantitatively by GC-MS.

- $100 \%$ batch (16.93 g to make $15 \mathrm{~g}$ glass)

- $70 \%$ batch - $30 \%$ cullet (16.35 g to make 15 g glass)

- $50 \%$ batch - $50 \%$ cullet (15.97 g to make 15 g glass)

The \%cullet is calculated based on the final glass weight, for example, the $50 \%$ batch $50 \%$ cullet consists of an $8.47 \mathrm{~g}$ of batch raw materials to produce $7.5 \mathrm{~g}$ of glass and $7.5 \mathrm{~g}$ of cullet. The particle size of glass cullet used in the batch expansion study was kept between 0.84 and $2 \mathrm{~mm}$ (10 to $20 \mathrm{mesh}$ ). This particle size was decided as a compromise between a better uniformity of batch materials-glass cullet contact area with a fine particle size and closer simulation of production batches with a large size of up to several $\mathrm{cm}$. 


\section{Heat Capacity and Heat of Fusion}

DSC analysis was performed in two different modes with the ambient flow rate of 10 $\mathrm{ml} / \mathrm{min}$ of $\mathrm{N}_{2}$ using Netzsch STA 409C: 1) a simultaneous TGA-DSC mode was performed for all three batches listed below at a constant heating rate of $5^{\circ} \mathrm{C} / \mathrm{min}$ from room temperature to $1450^{\circ} \mathrm{C}$ and 2) a heat capacity $(C p)$ mode was performed on the $100 \%$ batch and the glass cullet at a constant heating rate of $20^{\circ} \mathrm{C} / \mathrm{min}$ from room temperature to $1450^{\circ} \mathrm{C}$. Approximately 50- to 56-mg samples to give $\sim 50 \mathrm{mg}$ of glass were used for each run. The glass cullets used in DSC analysis were those finer particles that passed 20 mesh $(0.84 \mathrm{~mm})$.

- $100 \%$ batch ( $56 \mathrm{mg}$ to make $50 \mathrm{mg}$ of glass)

- $50 \%$ batch $-50 \%$ cullet ( $\sim 53 \mathrm{mg}$ to make $50 \mathrm{mg}$ of glass)

- $100 \%$ glass cullet $(\sim 50 \mathrm{mg})$

For the heat-capacity measurements, a simplified method was used instead of the more rigorous American Society for Testing and Materials (ASTM) method (specified as ASTM E 1269-01) to save time. The simplified method is expected to give a little higher error of $\pm 10 \%$ compared to $\pm 6 \%$ of the ASTM method. Because the DSC method to measure the heat capacity for the materials with extensive phase change and reactions involving solid, liquid, and gas phases is not a standard procedure, it should be considered as a first approximation without any validation. 


\section{Results and Discussion}

The results of TGA and DTA tests on eight batches are in Figures 1 through 8 . Figures 9 through 16 are the plots of TGA weight change and the gas evolution rate as a function of temperature during TGA-DTA runs. The TGA weight-loss curves are included in Figures 9 through 16 for direct comparison with gas-evolution curves. The major batch gas was $\mathrm{CO}_{2}$ from the decomposition of soda ash and limestone. The evolution of $\mathrm{CO}$ gas follows the $\mathrm{CO}_{2}$ release at a rate of roughly $5 \%$ of $\mathrm{CO}_{2}$. All the TGA weight loss curves show a very good match with the gas-evolution rates. In the EGA study from TGA-DTA, the refining gases are not detected because the amount of $\mathrm{SO}_{2}$ and $\mathrm{O}_{2}$ gases evolved from a small-sized batch are below the detection limit of the GC-MS system. Some of the major points to note are:

- The small endothermic peak centered at $575^{\circ} \mathrm{C}$ that appears in the DTA of every batch containing sand is the well known $\alpha-\beta$ inversion of quartz.

- The weight loss curve in the $100 \%$ batch (Figure 1) shows two major weight-loss segments centered at $650^{\circ} \mathrm{C}$ and $830^{\circ} \mathrm{C}$, which are attributed to the decomposition of limestone and soda ash, respectively, generating $\mathrm{CO}_{2}$ and $\mathrm{CO}$ gases. These two segments exactly match the weight-loss segments observed in two-component batches of sandlimestone and sand-soda ash shown in Figures 2 and 3. The same trend can also be observed from gas-evolution curves; see Figures 9, 10, and 11.

- In two-component batches containing limestone, there is no significant difference in the temperature range of weight-loss reactions between batches containing sand and feldspar. (Batch \#3 compared to \#5). However, in the feldspar-soda ash batch (\#4, Figure 4), the melting reactions start at a lower temperature and continue to a higher temperature compared to the sand-soda ash batch (\#2, Figure 2). The "residual" reactions continue up to $1100^{\circ} \mathrm{C}$, which is not observed in the sand-soda ash batch. The residual reactions were also detected by EGA as shown in Figure 12 compared to Figure 10. Figure 17 compares the $\mathrm{CO}_{2}$ evolution rates in all the two-component batches tested in this study.

- The three-component batch, Batch \#6 (Figure 6) is similar to the $100 \%$ batch (\#1, Figure 1) with the two major weight-loss segments. The extent of the first weight-loss segment is larger in $\# 6$ than in the $100 \%$ batch just because of the higher limestone fraction in \#6. However, the feldspar-containing three-component batch (\#7, Figure 7) shows different reaction characteristics. Although the first segment is similar to \#6, the second segment of weight loss (by soda ash) shows delayed reactions that continue to a higher temperature region up to $1100^{\circ} \mathrm{C}$ (Figures 7 and 15 compared to Figures 6 and 14), which is the same as observed in two-component batches. It is likely that the delayed reaction in feldspar-containing batches is caused by the formation of sodium-aluminum silicate phases. Figure 18 compares the $\mathrm{CO}_{2}$ evolution rates in a $100 \%$ batch and threecomponent batches.

- When the three-component Batch \#8 with burnt dolomite is compared to that with limestone (\#6), the batch with burnt dolomite caused the soda ash-silica reaction to start at a slightly lower temperature, as compared in Figure 19. 
Figures 20 through 22 are the plots of the change of the gas-evolution rate and batch volume as a function of temperature for the three batches with 0,30 , and $50 \mathrm{wt} \%$ glass cullet. The major batch gases $\left(\mathrm{CO}_{2}\right.$ and $\left.\mathrm{CO}\right)$ from the decomposition of soda ash and limestone evolve in a temperature range of roughly 700 to $1100^{\circ} \mathrm{C}$ with the peak evolution rate at about $900^{\circ} \mathrm{C}$.

Batch expansion typically starts after the main stream of $\mathrm{CO}_{2}$ gases evolve. This was first suggested by Kim and Hrma (1990) and later confirmed by Laimböck (1998). Figures 23 through 27 show the effect of cullet content on batch expansion and the evolution rate of different gases. Expansion temperature, defined as the intersection of the tangent to the rising slope of relative batch volume with the baseline volume, decreases with increasing cullet content, from $960^{\circ} \mathrm{C}$ to 925 and $880^{\circ} \mathrm{C}$. This can be attributed to the early formation of viscous melt that can trap the evolved gases at a higher cullet content. Interestingly, the evolution of batch-reaction gases $\left(\mathrm{CO}_{2}\right.$ and $\left.\mathrm{CO}\right)$ started at the same temperature with approximately the same initial rising slope regardless of cullet content, but reached the peak earlier and then ended earlier at a lower temperature with the increase of cullet content, as shown in Figures 24 and 25. However, no noticeable effect of cullet content on the maximum batch expansion was observed. The combined effect of cullet content, i.e., the decrease of the expansion temperature and early end of $\mathrm{CO}_{2}$ and $\mathrm{CO}$ evolution with increasing cullet content, resulted in similar maximum expansion.

The refining gases from sulfate decomposition, $\mathrm{SO}_{2}$ and $\mathrm{O}_{2}$, began to evolve at approximately $1100^{\circ} \mathrm{C}$ and continued to the final temperature used in this study. As shown in Figures 26 and 27, there was no apparent trend regarding the effect of cullet content on the $\mathrm{SO}_{2}$ and $\mathrm{O}_{2}$ evolution rate, which might provide valuable information on the effect of cullet content on the refining behavior. The severe fluctuation of the evolution rate makes it impossible to catch a small difference in gas-evolution temperature and gas-evolution rate that might exist between batches with a different cullet content. This instability may be attributed to the bubbles busting at the melt surface. This project was not designed to study refining. For a more detailed study on refining (for example, to study the effect of cullet content on the refining behavior) would require modified test methods specifically designed to overcome the instability caused by bubble bursting.

The effect of batch size on batch reactions can be considered by comparing the $\mathrm{CO}_{2}$ and $\mathrm{CO}$ evolution rates obtained from two different tests of TGA-DTA and batch expansion as shown in Figure 28. The temperature of gas evolution shifts to a higher range by the increased batch size, reflecting the fact that heat transfer is one of the major factors that determine the batch reaction rates.

The weight-loss and energy-change curves from simultaneous TGA-DSC tests are in Figures 29 through 31. The simultaneous TGA-DSC tests were not included in the initial plan for this project but were performed as a preliminary step before the heat-capacity-mode DSC tests. The TGA result in the $100 \%$ batch is in good agreement with that from a simultaneous TGA-DTA run. The DSC curves in $100 \%$ batch and $50 \%$ batch- $50 \%$ cullet show three major peaks that correspond to the $\alpha-\beta$ inversion of quartz $\left(\sim 575^{\circ} \mathrm{C}\right)$ and the decomposition of limestone $\left(\sim 700^{\circ} \mathrm{C}\right)$ and soda ash $\left(\sim 850^{\circ} \mathrm{C}\right)$, similar to the curves from TGA-DTA. The DSC 
curve of $100 \%$ cullet shows two inflection points, indicating phase transformation - the first is believed to be the glass-transition temperature at $560^{\circ} \mathrm{C}$, but the second at $\sim 730^{\circ} \mathrm{C}$ may be related to the sintering of glass particles. Figure 32 compares the three DSC curves.

The heat of fusion $\left(\Delta H_{l}, \mathrm{~kJ} / \mathrm{kg}\right.$ glass $)$ is defined as the energy required to transform a certain amount $[(1+b) \mathrm{kg}]$ of batch material at room temperature to $1 \mathrm{~kg}$ of glass melt and $b \mathrm{~kg}$ of gas at temperature $T$.

$$
[(1+b) \mathrm{kg} \text { of batch }]\left(T_{\text {room }}\right) \rightarrow(1 \mathrm{~kg} \text { of glass melt })(T)+(b \mathrm{~kg} \text { of gas })(T) \quad\left(\Delta H_{l}\right)
$$

This value involves:

- the heat necessary to increase the temperature of the raw materials and intermediary phases to their reaction temperatures and the heat necessary to increase the temperature of the end products to the final temperature $\mathrm{T}$

- the heat of dissociation for raw materials and chemical reactions

- the heat of fusion involved in the formation of the first melts of certain components and the mixing enthalpy involved in the formation of the homogeneous glass melt.

Figure 33 shows the $C p$ measured by DSC as a function of temperature for the glass cullet and $100 \%$ batch. The heat capacity curve of the glass cullet shows two points of abrupt increase of the slope-first at $550^{\circ} \mathrm{C}$ due to glass transition and second at $750^{\circ} \mathrm{C}$, presumably due to sintering of glass particles, as were also observed in a simultaneous TGA-DSC mode. Assuming that there are no major phase changes involving a significant reaction heat up to approximately $500^{\circ} \mathrm{C}$, the $C p(T)$ of a $100 \%$ batch up to this temperature can be regarded as an average $C p$ of all the batch materials.

The DCS runs for $C p$ measurement were unintentionally stopped at about $1200^{\circ} \mathrm{C}$ because of an error in equipment operation. Based on the information that the $C p$ of glass at above $600^{\circ} \mathrm{C}$ is approximated as a constant (Scholze 1990), the $C p$ data in the temperature range from 1100 to $1200^{\circ} \mathrm{C}$ was used to extrapolate the data to $1500^{\circ} \mathrm{C}$. Because the $100 \%$ batch had the same $C p$ value as the glass at about $1200^{\circ} \mathrm{C}$ (marked as $\mathrm{X}$ in Figure 33), this was used as a starting point to use the same value as the glass cullet. The extrapolated $C p$ curves are in Figure 34.

The heat of fusion of glass cullet is a simple integration of $C p(T)$ over the temperature range of interest. The same integration of $C p(T)$ of a $100 \%$ batch over temperature would include most of the energy involved in $\Delta H_{l}$ except for the energy required to heat the evolved gases from the temperature of gas evolution to the temperature $T$. (This involves the assumption that the $C p$ measurements were not disturbed by the phase transformation, chemical reactions, or gas generations.) Then the total energy obtained from DSC $C p(T)$ measurements is given as:

$$
\Delta H_{D S C}(T)=\int_{298}^{T} C p(T) d T=\Delta H_{l}(\mathrm{~T})-\Delta H_{E G}(T)
$$


where $\Delta H_{E G}(T)$ is the energy required to heat the evolved gases from the temperature of gas evolution to the temperature $T$.

Models have been developed to calculate the $\Delta H_{1}$ from the batch composition and the thermochemical data of the phases involved in batch melting reactions. Below is a summary of the model developed by Madivate (1998). The calculation is based on the breakdown of Reaction (1) into three reactions:

$$
\begin{array}{lr}
{[(1+b) \mathrm{kg} \text { of batch }]\left(T_{\text {room }}\right) \rightarrow(1 \mathrm{~kg} \text { of glass })\left(T_{\text {room }}\right)+(b \mathrm{~kg} \text { of gas })\left(T_{\text {room }}\right)} & \left(\Delta H_{R}\right) \\
(1 \mathrm{~kg} \text { of glass })\left(T_{\text {room }}\right) \rightarrow(1 \mathrm{~kg} \text { of glass melt })(T) & \left(\Delta H_{\text {glass }}\right) \\
(b \mathrm{~kg} \text { of gas })\left(T_{\text {room }}\right) \rightarrow(b \mathrm{~kg} \text { of gas })(T) & \left(b \Delta H_{\text {gas }}\right)
\end{array}
$$

where $T$ is the absolute temperature. Then $\Delta H_{1}$ is calculated as a sum of the $\Delta H$ values in reactions (3) to (5):

$$
\Delta H_{l}(T)(\mathrm{kJ} / \mathrm{kg} \text { of glass })=\Delta H_{R}\left(T_{\text {room }}\right)+\Delta H_{\text {glass }}(T)+\Delta H_{\text {gas }}(T)
$$

Further, the $\Delta H_{R}$ is calculated as a sum of two terms:

$$
\Delta H_{R}=\Delta H_{d}+\Delta H_{g}
$$

where $\Delta H_{d}$ represents the energy necessary to decompose the raw materials to their respective oxides and $\Delta H_{g}$ represents the energy involved in the formation of the vitreous phase from the oxides.

All the data necessary to calculate the $\Delta H$ values for typical soda-lime silicate glasses are given in Madivate (1998) and Madivate et al. (1996). Before proceeding to calculate the $\Delta H_{l}(T)$ of the glass used in this study, one of the glass compositions given in Madivate (1998) and Madivate et al. (1996) was used to check the accuracy of our calculation. During this calculation, the major discrepancy of the given coefficients was found between the two references. The discrepancy and the temporary solutions to resolve this discrepancy are described in Appendix A. ${ }^{1}$

Figure 35 compares the $\Delta H_{l}(T)$ values obtained for a clear flat glass (Glass I) used in Madivate (1998). The calculated values in this study are in reasonable agreement with the reported value in Madivate (1998), indicating that the present calculation is close enough although not accurate to the exact values. Figure 35 also shows the results of the $\Delta H_{l}(T)$ calculation on the glass used in this study using the model (Equation (5)) by Madivate (1998) and using Equation (2) and $C p(T)$ values obtained from the DSC measurement (Figure 34). To calculate $\Delta H_{E G}(T)$ in Equation (2), it was assumed that the gases from the decomposition

\footnotetext{
${ }^{1}$ Because the resolution in Appendix A is not verified by the original authors nor supported by additional data, the $\Delta H_{I}(T)$ values calculated for the glass in this report should be treated as an exercise rather than the data for application until they are validated.
} 
of limestone and soda ash were all $\mathrm{CO}_{2}$ and that the gases from each material evolve at once at the temperature of peak gas generation. The peak-gas-generation (or peak-reaction) temperatures obtained from the DSC curve were used: $780^{\circ} \mathrm{C}$ for limestone and $870^{\circ} \mathrm{C}$ for soda ash. These were higher than the temperatures found in TGA-DTA with EGA, which are likely caused by a higher heating rate used in $\mathrm{Cp}$ measurement $\left(20^{\circ} \mathrm{C} / \mathrm{min}\right.$ compared to $5^{\circ} \mathrm{C} / \mathrm{min}$ in TGA-DTA). The maximum deviation from each other within the temperature range in Figure 35 is about $10 \%$, which is close to the expected error of $\pm 10 \%$ in DSC $\Delta H_{I}(T)$ measurements. This is an encouraging result considering that several assumptions were involved in these calculations.

The $\Delta H_{I}(T)$ value calculated by integrating the $C p(T)$ of the glass cullet corresponds to $\Delta H_{\text {glass }}$ in Equation (4). Figure 36 compares the $\Delta H_{\text {glass }}$ of glass cullet calculated from the $C p(T)$ and the $\Delta H_{\text {glass }}$ calculated during the course of calculating the $\Delta H_{I}(T)$ of the glass batch. They show general agreement with each other within the temperature range used.

Based on comparisons in Figures 35 and 36, it may be suggested that the DSC $C p$ measurements can be used to calculate the $\Delta H_{I}(T)$ values of the glass batch containing raw materials. However, it has been realized that it is necessary to improve DCS methods in order to obtain accurate $\mathrm{Cp}$ data and the calculated data need to be fully validated. Once this method is well established and validated, it can provide a very economical way of deriving the heat of fusion data for many different technical glass batches. 


\section{Conclusions}

From the study of batch expansion and TGA-DTA combined with evolved gas analysis, the batch-reaction data on a soda-lime-silicate glass composition have been obtained including the effect of the cullet ratio on the reaction rate of cullet-containing batches. The batch-reaction data obtained in this study can be incorporated into the batch part of the glass furnace model. The methodology developed during this study with a soda-lime glass batch can be applied to other technical glass batches. It was suggested that test methods should be modified for the detailed study of refining by refining agents.

It has been suggested that DSC can be used to measure the heat capacity of the glass cullet and the batch of raw materials, and this measurement can be used to estimate the heat of fusion needed for the batch model. With the improvement of measurement accuracy and the validation of the assumptions involved in the calculations, the combined method of applying DSC $C p$ measurements and thermochemical calculation would become a valuable tool for obtaining data for batch model calculation for many different technical glass batches. 


\section{References}

ASTM E 1269 - 01, "Standard Test Method for Determining Specific Heat Capacity by Differential Scanning Calorimetry."

Hong, K. S. and R. E. Speyer, "Thermal Analysis of Reactions in Soda-Lime Silicate Glass Batches Containing Melting Accelerants: I, One- and two-component systems," J. Am. Ceram. Soc., 76 [3] 598-604 (1993).

Hong, K. S., S. W. Lee, and R. E. Speyer, "Thermal Analysis of Reactions in Soda-Lime Silicate Glass Batches Containing Melting Accelerants: II, Multicomponent systems," J. Am. Ceram. Soc., 76 [3] 605-608 (1993).

Izak, P., P. Hrma, and M. J. Schweiger, "Chapter 19 - Kinetics of Conversion of High-Level Waste to Glass," ACS Symposium Series 778, 314-328 (2001a).

Izak, P., P. Hrma, B. W. Arey, and T. J. Plaisted, “Effect of Feed Melting, Temperature History, and Minor Component Addition on Spinel Crystallization in High-Level Waste Glass,” J. Non-Cryst. Solids, 289 17-29 (2001b).

Kawachi, S., M. Kato, and Y. Kawase, "Evaluation of Reaction Rate of Refining Agents," Glastech. Ber. Glass Sci. Technol., 72 [6] 182-87 (1999).

Kim, D. and P. Hrma, "Volume Changes during Batch to Glass Conversion," Am. Ceram. Soc. Bull., 69 [6] 1039-43 (1990).

Krämer, F., "Gas Profile Measurements as a Means of Determining Gas Evolution During Glass Melting," Glastechn. Ber., 53 [7] 177-188 (1980).

Laimböck, P., "Foaming of Glass melts," Ph.D. Thesis, University of Technology, Eindhoven, 1998.

Laimböck, P., "Fining and Foaming Behavior of Sulfate Fined Glass Melts," Proceedings of the ICG 2000 Amsterdam, Glass in the Millennium, Amsterdam (2000).

Madivate, C., F. Müller, and W. Wilsmann, "Thermochemistry of the Glass Melting Process Energy Requirement in Melting Soda-Lime-Silica Glasses from Cullet-Containing Batches," Glastech. Ber. Glass Sci. Technol., 69 [6] 167-78 (1996).

Madivate, C., "Calculation of the Theoretical Energy Requirements for Melting Technical Silicate Glasses," J. Am. Ceram. Soc., 81 [12] 3300-306 (1998).

Mukerji, J., A. K. Nandi, and K. D. Sharma, "Reaction in Container Glass Batch," Am. Ceram. Soc. Bull., 59 [8] 790-93 (1980). 
Scholtze, H. 1990. Glass Nature, Structure, and Properties, Springer, New York.

Thomasson, C. V. and F. W. Wilburn, "The Application of Differential Thermal Analysis and Thermogravimetric Analysis to the Study of Reactions between Glass-Making Materials, Part 2. The Sodium Carbonate-Silica System with Minor Batch Additions," Phys. Chem. Glasses, 1 [2], 52-69 (1960).

Warburton, R. S. and F. W. Wilburn, "The Application of Differential Thermal Analysis and Thermogravimetric Analysis to the Study of Reactions between Glass-Making Materials, Part 3. The Calcium Carbonate-Silica System," Phys. Chem. Glasses, 2 [4], 126-31 (1961).

Warburton, R. S. and F. W. Wilburn, "The Application of Differential Thermal Analysis and Thermogravimetric Analysis to the Study of Reactions between Glass-Making Materials, Part 3. The Calcium Carbonate-Silica-Alumina System," Phys. Chem. Glasses, 4 [3], 91-98 (1963).

Wilburn, F. W. and C. V. Thomasson, "The Application of Differential Thermal Analysis and Thermogravimetric Analysis to the Study of Reactions between Glass-making Materials, Part I. The sodium Carbonate-Silica System," J. Soc. Glass Tech., 42, 158T-175T (1958).

Wilburn, F. W., S. A. Metcalfe, and R. S. Warburton, "Differential Thermal Analysis, Differential Thermogravimetric Analysis, and High Temperature Microscopy of Reactions Between the Major Components of Sheet Glass Batch," Glass Technol., 6 [4] 107-14 (1965). 


\section{Appendix A. Discrepancy of data between two references, Madivate (1998) and Madivate et al. (1996)}

Table II in Madivate (1998) lists the factors $a_{i}$ and $b_{i}$ to calculate $\Delta H_{\text {glass }}$ using the following equation:

$$
\Delta H_{\text {glass }}(T)=\Sigma(\% \text { oxide })_{i} a_{i}+\Sigma\left[(\% \text { oxide })_{i} b_{i}\right] T
$$

where (\%oxide) $)_{i}$ is the content of a given oxide in the glass. On the other hand, Table 6 in Madivate et al. (1996) shows the values of $e_{i}=\Sigma(\% \text { oxide })_{i} a_{i}$ and $f_{i}=\Sigma\left[(\% \text { oxide })_{i} b_{i}\right]$, which are used to directly calculate $\Delta H_{\text {glass }}(T)$ (denoted as $\Delta H_{b}(T)$ in Madivate et al. (1996)).

Table A 1 compares the $e_{i}$ and $f_{i}$ values calculated from the $a_{i}$ and $b_{i}$ given in Table II of Madivate (1998) for the six glasses used in both references with the $e_{i}$ and $f_{i}$ values given in Table 6 in Madivate et al. (1996). The calculation of $\Delta H_{l}(T)$ for one of the glasses used in both references using the different set of $f_{i}$ values in Table A1 revealed that the $b_{i}$ values in Table II of Madivate (1998) are in error.

Table A2 shows the $b_{i}$ values back calculated from the $f_{i}$ values given in Table 6 of Madivate et al. (1996) together with the $b_{i}$ values in Table II of Madivate (1998). These back calculated $b_{i}$ values were used for the calculation of $\Delta H_{l}(T)$ for the glass composition tested in this study. Because there were seven components while $f_{i}$ data were available only for six glasses, the $b_{i}$ values for only six components were calculated and the $\mathrm{Fe}_{2} \mathrm{O}_{3}$ coefficient was assumed to be correct. Therefore there is a chance that this back calculation conducted in this Appendix may not be accurate.

It was also noticed that the $e_{i}$ values for two glasses (III and IV) show a discrepancy between the references as shown in Table A1. It was not attempted to find the resolution of this discrepancy.

Table A1. Comparison of the $e_{i}$ and $f_{i}$ values given in Table 6 of Madivate et al. (1996) with the values calculated from Table II of Madivate (1998)

\begin{tabular}{|c|c|c|c|c|}
\hline \multirow{2}{*}{ Glass } & \multicolumn{2}{|c|}{$e_{i}$} & \multicolumn{2}{c|}{$f_{i}$} \\
\cline { 2 - 5 } & Given* & Calculated $*$ & Given $^{*}$ & Calculated $* *$ \\
\hline I & -614.0 & -616.0 & $\mathbf{1 . 3 7 3}$ & $\mathbf{0 . 6 4 5}$ \\
\hline II & -1121.4 & -1123.4 & $\mathbf{1 . 7 6 7}$ & $\mathbf{1 . 0 5 1}$ \\
\hline III & $\mathbf{- 8 1 0 . 3}$ & $\mathbf{- 9 0 9 . 0}$ & $\mathbf{1 . 5 3 9}$ & $\mathbf{0 . 8 9 5}$ \\
\hline IV & $\mathbf{- 6 8 2 . 9}$ & $\mathbf{- 5 9 9 . 8}$ & $\mathbf{1 . 4 2 8}$ & $\mathbf{0 . 7 5 6}$ \\
\hline V & -888.1 & -880.4 & $\mathbf{1 . 6 0 3}$ & $\mathbf{0 . 9 2 9}$ \\
\hline VI & -756.5 & -763.0 & $\mathbf{1 . 5 2 1}$ & $\mathbf{0 . 8 7 0}$ \\
\hline
\end{tabular}

* Given in Table 6 of Madivate et al. (1996)

**Calculated from Table II of Madivate (1998) 
Table A2. Comparison of the $e_{i}$ and $f_{i}$ values given in Table 6 of Madivate et al. (1996) with the values calculated from Table II of Madivate (1998)

\begin{tabular}{|l|r|r|r|}
\hline & \multicolumn{2}{|c|}{ Given* } & Calculated \\
\hline Coxide & \multicolumn{1}{|c|}{$a_{i}$} & \multicolumn{1}{c|}{$b_{i}$} & \multicolumn{1}{c|}{$\boldsymbol{b}_{\boldsymbol{i}}$} \\
\hline $\mathrm{SiO}_{2}$ & 67.7 & -0.014 & $\mathbf{- 0 . 0 2 2}$ \\
\hline $\mathrm{Na}_{2} \mathrm{O}$ & -133.3 & -0.027 & $\mathbf{0 . 0 6 6}$ \\
\hline $\mathrm{K}_{2} \mathrm{O}$ & -17.9 & -0.159 & $\mathbf{- 0 . 0 9 2}$ \\
\hline $\mathrm{CaO}$ & -264.0 & 0.148 & $\mathbf{0 . 0 6 8}$ \\
\hline $\mathrm{MgO}$ & -224.4 & 0.124 & $\mathbf{0 . 2 6 5}$ \\
\hline $\mathrm{Al}_{2} \mathrm{O}_{3}$ & -365.1 & 0.250 & $\mathbf{0 . 5 4 0}$ \\
\hline $\mathrm{Fe}_{2} \mathrm{O}_{3}$ & -942.9 & 0.626 & $\mathbf{0 . 6 2 6}$ \\
\hline
\end{tabular}

*Given in Table II of Madivate (1998)

**Back calculated using the $f_{i}$ values given in Table 6 of Madivate et al. (1996) 


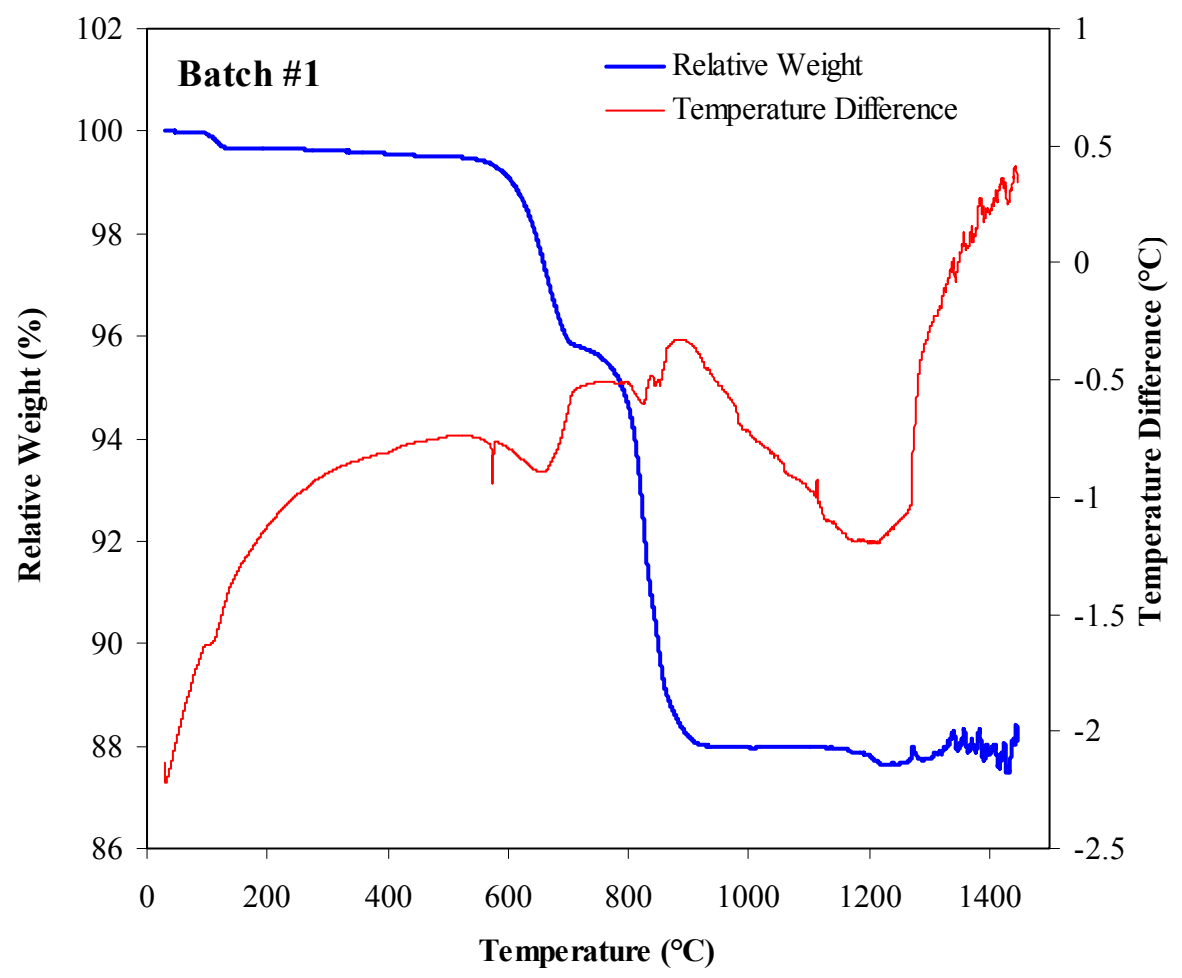

Figure 1. TGA and DTA of Batch \#1 (100\% Batch)

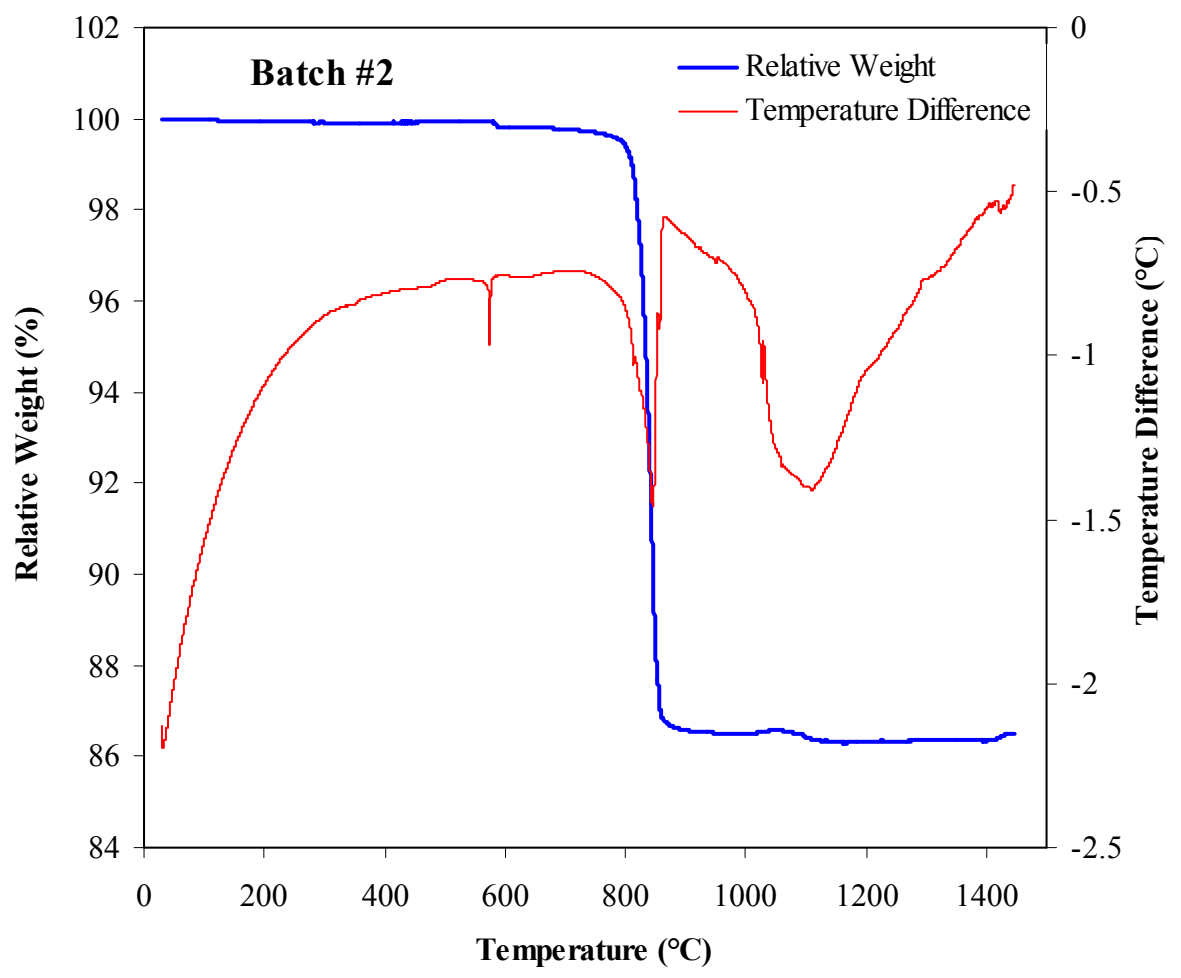

Figure 2. TGA and DTA of Batch \#2 (two parts sand and one part soda ash) 


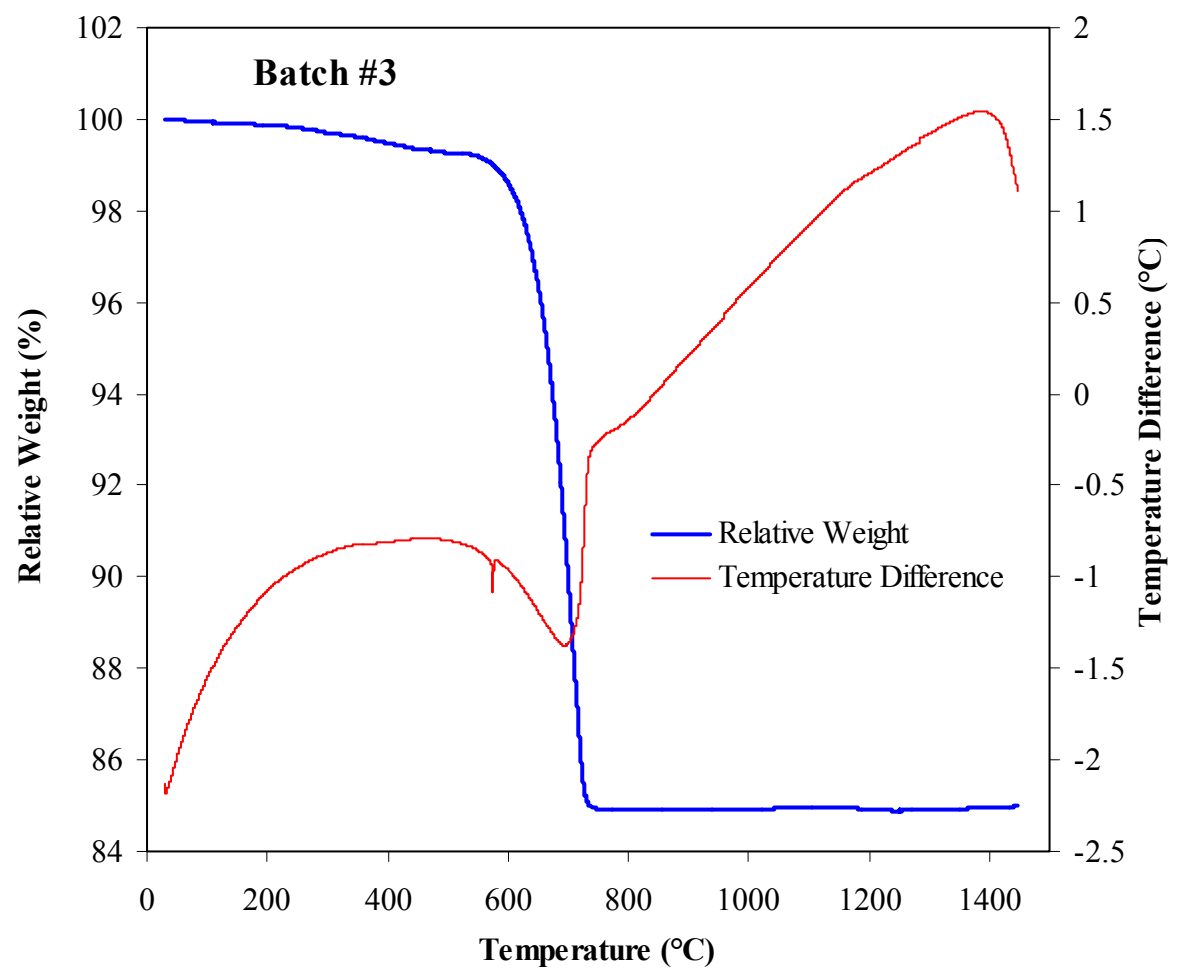

Figure 3. TGA and DTA of Batch \#3 (two parts sand and one part limestone)

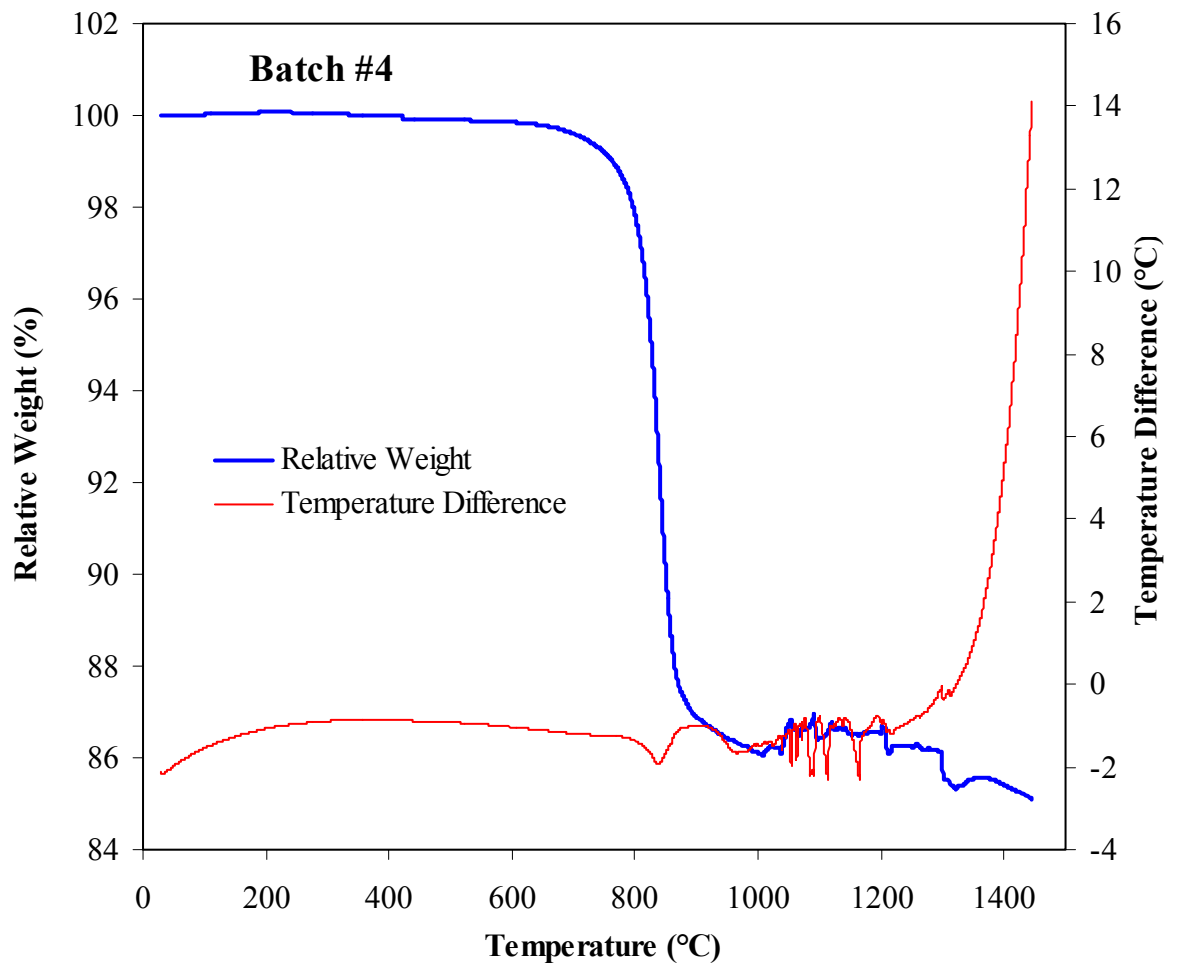

Figure 4. TGA and DTA of Batch \#4 (two parts feldspar and one part soda ash) 


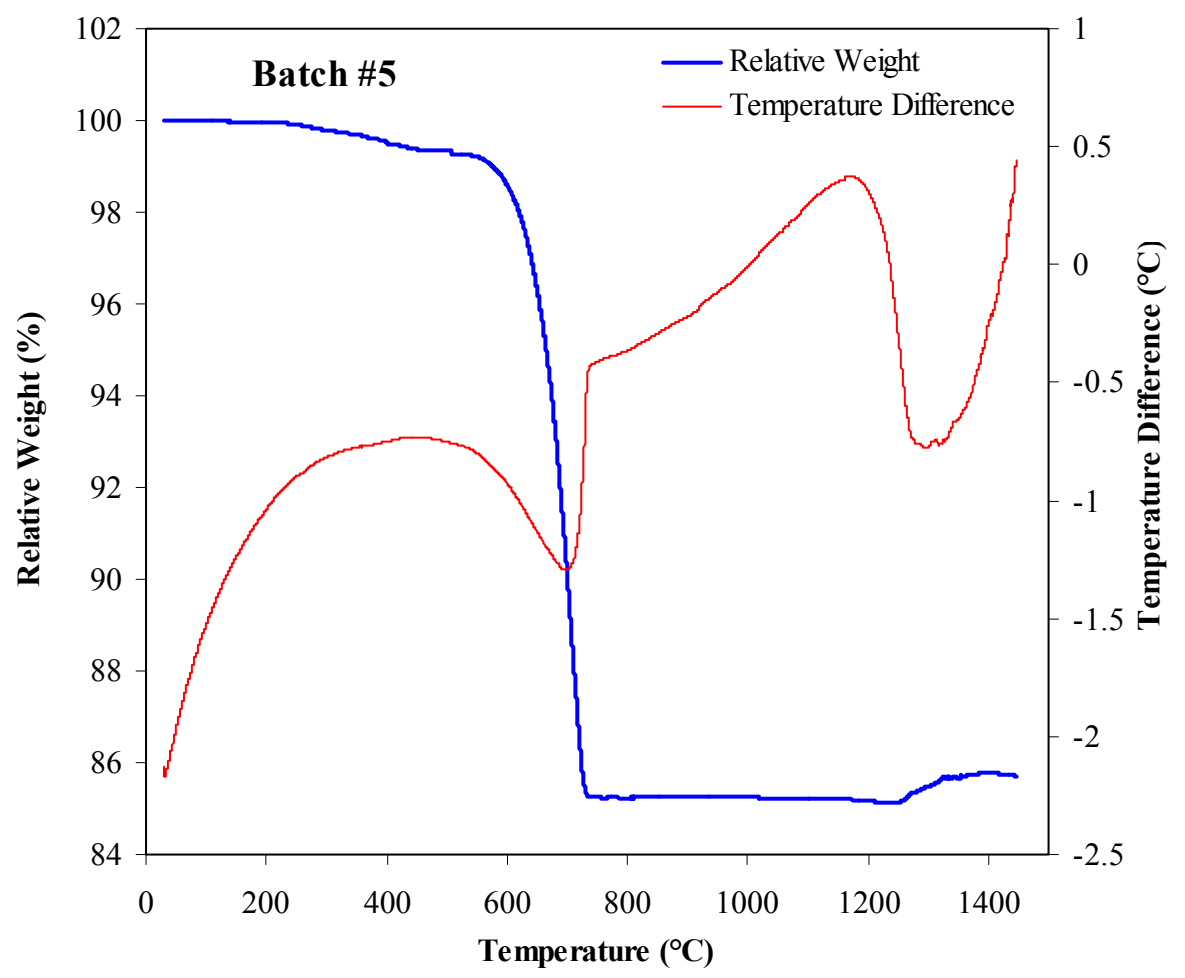

Figure 5. TGA and DTA of Batch \#5 (two parts feldspar and one part limestone)

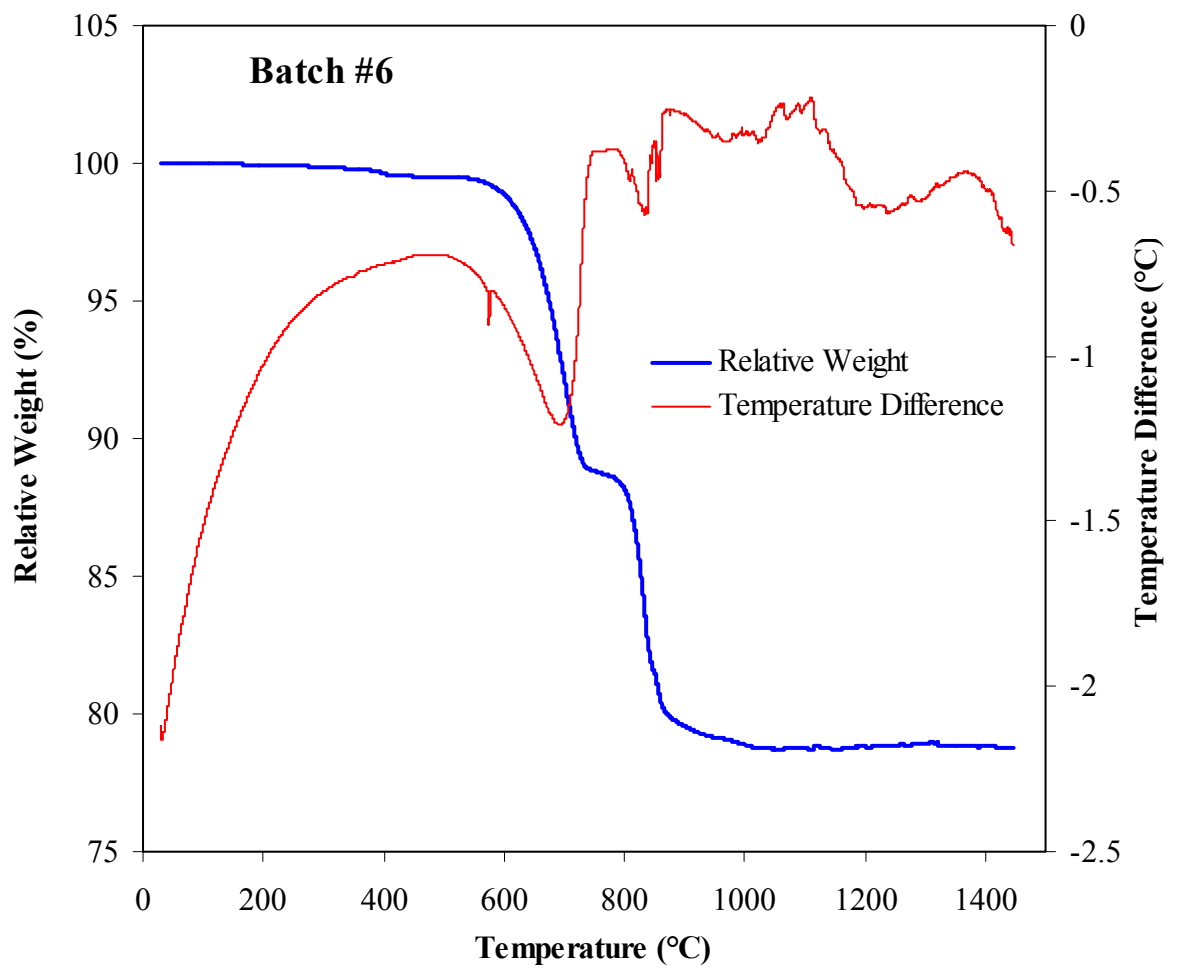

Figure 6. TGA and DTA of Batch \#6 (two parts sand, one part soda ash, and one part limestone) 


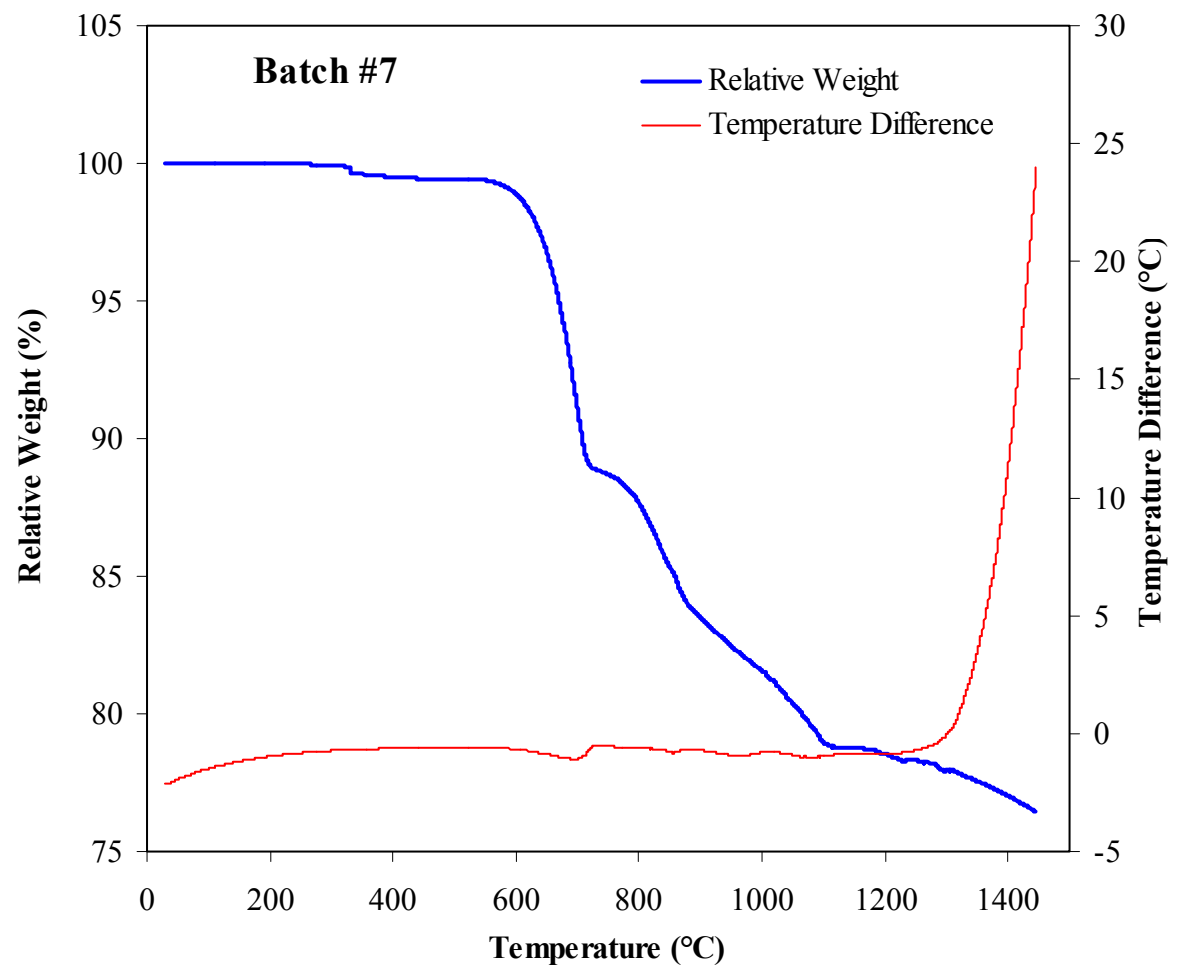

Figure 7. TGA and DTA of Batch \#7 (two parts feldspar, one part soda ash, and one part limestone)

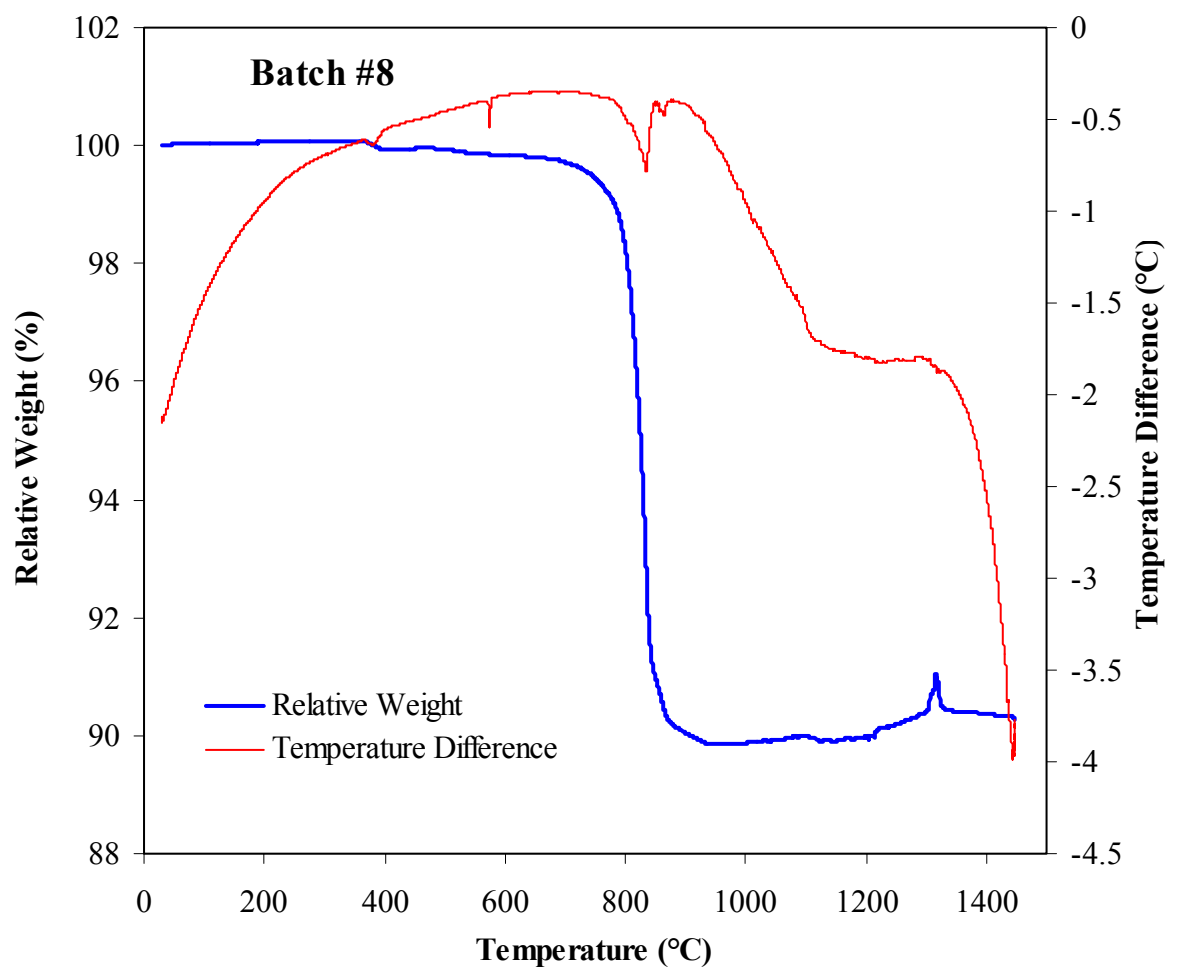

Figure 8. TGA and DTA of Batch \#8 (two parts sand, one part soda ash, and one part burnt lime) 


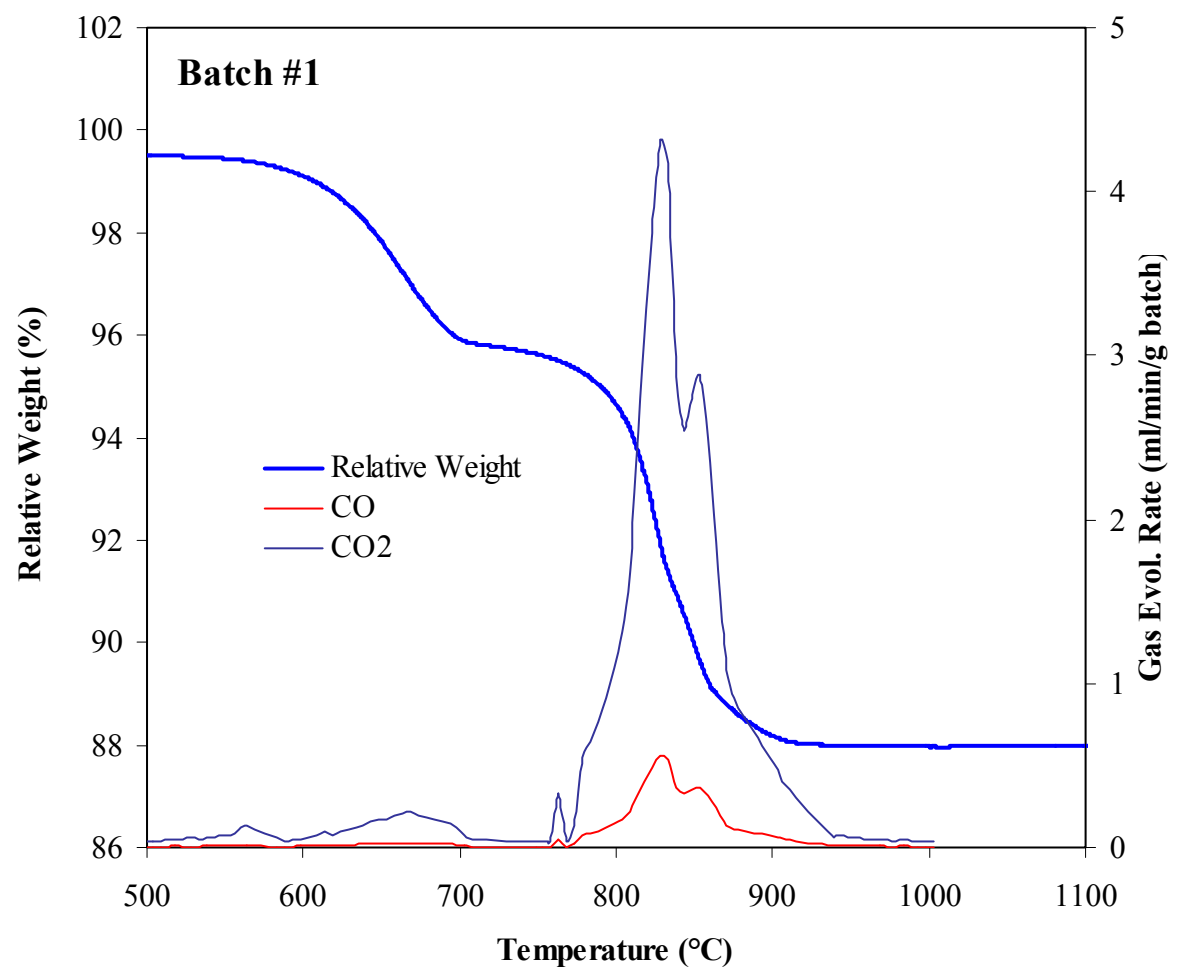

Figure 9. TGA and EGA of Batch \#1 (100\% Batch)

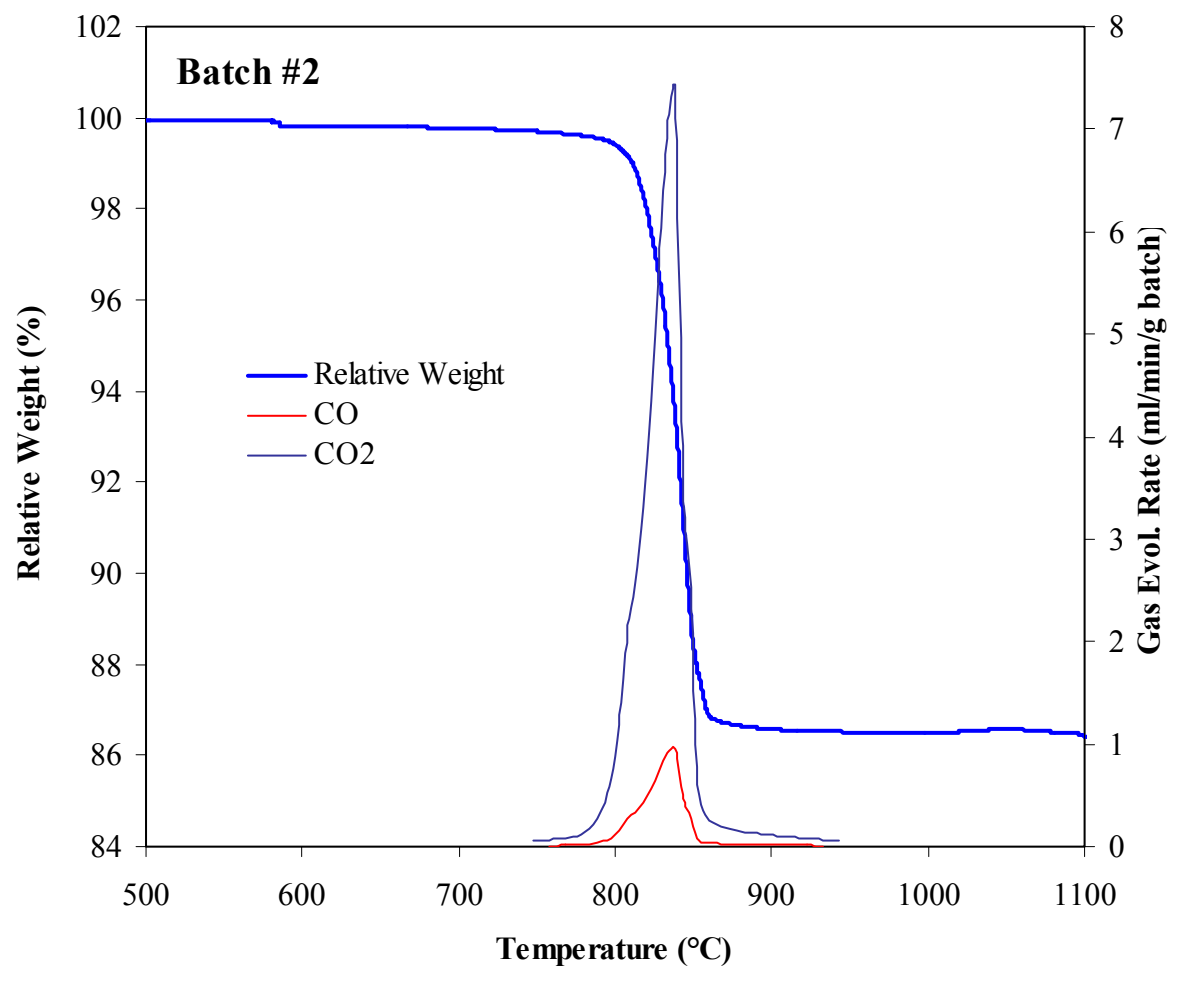

Figure 10. TGA and EGA of Batch \#2 (two parts sand and one part soda ash) 


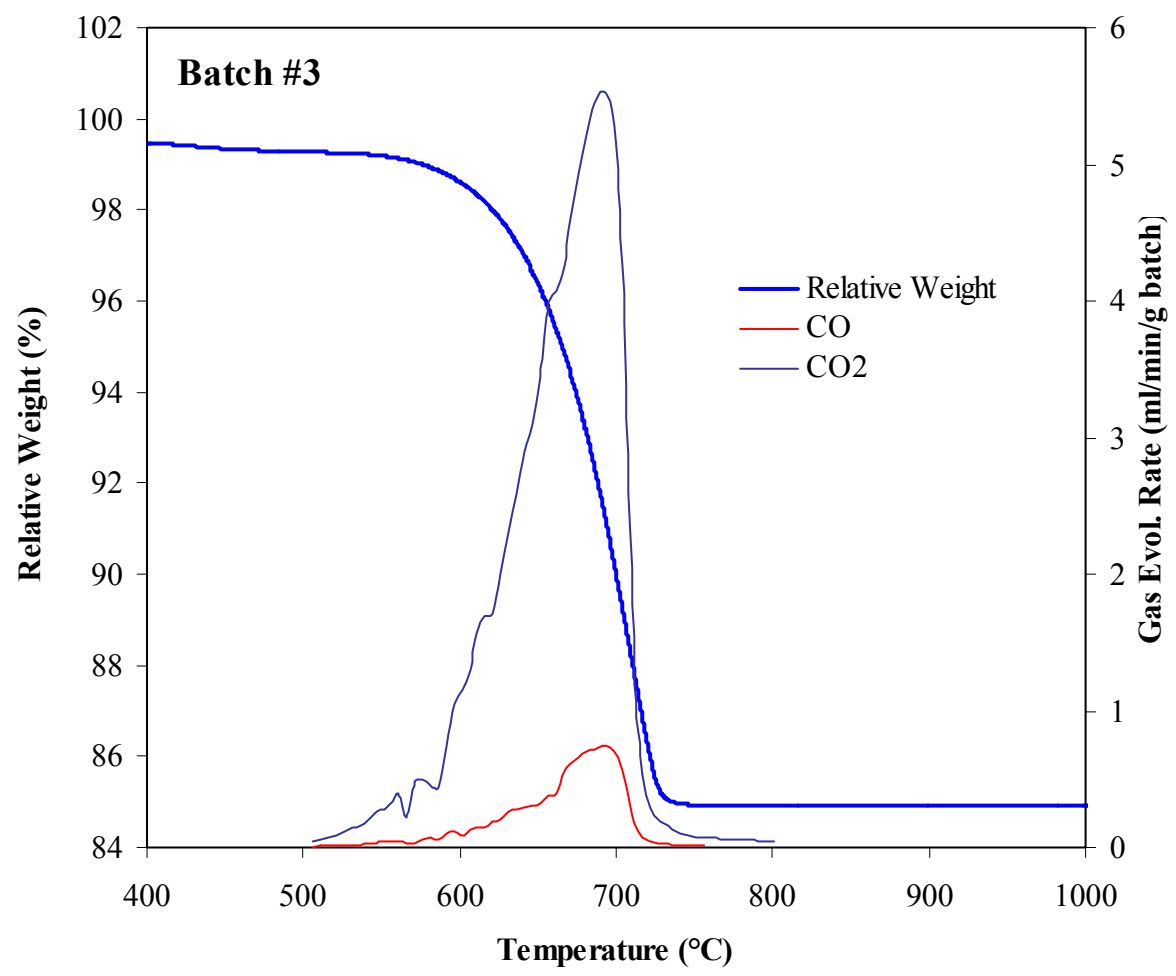

Figure 11. TGA and EGA of Batch \#3 (two parts sand and one part limestone)

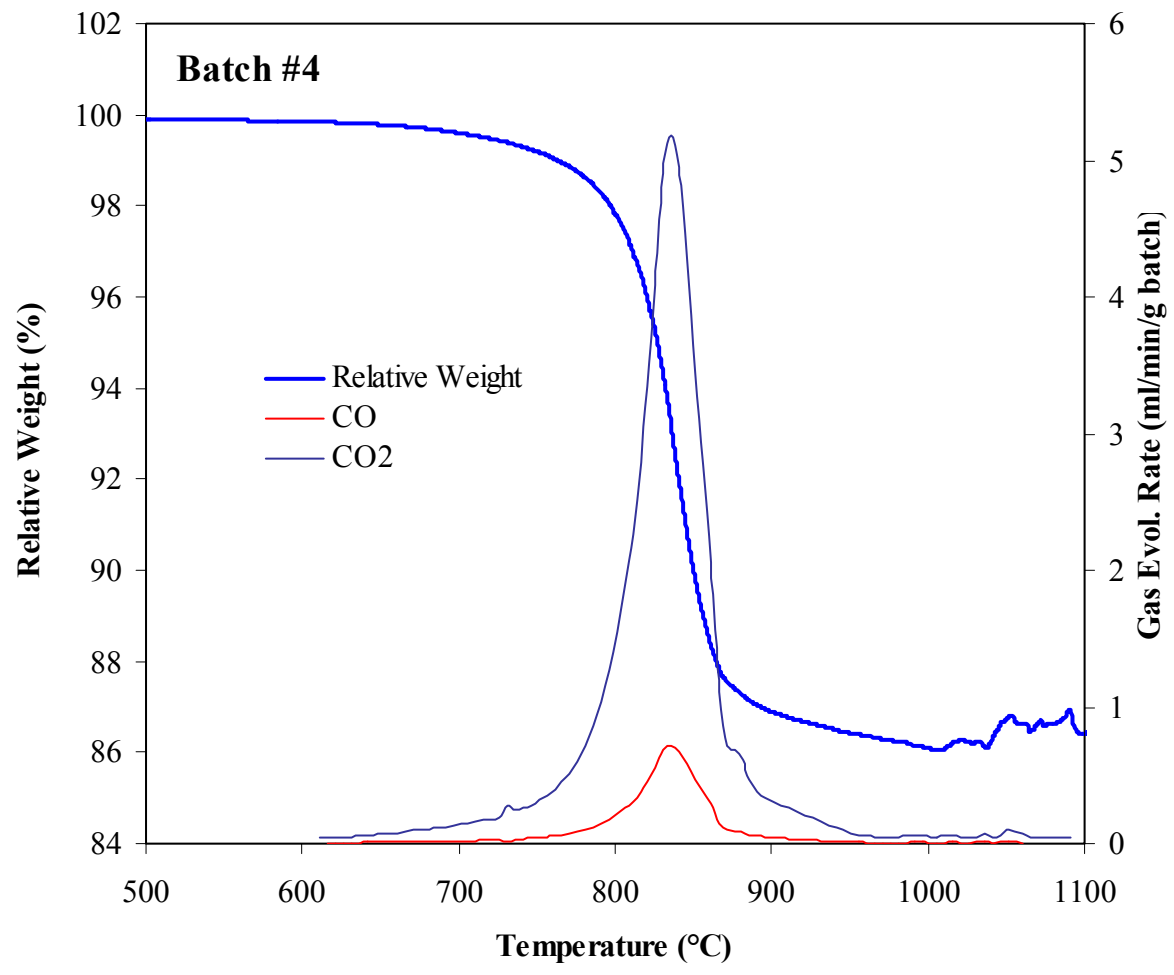

Figure 12. TGA and EGA of Batch \#4 (two parts feldspar and one part soda ash) 


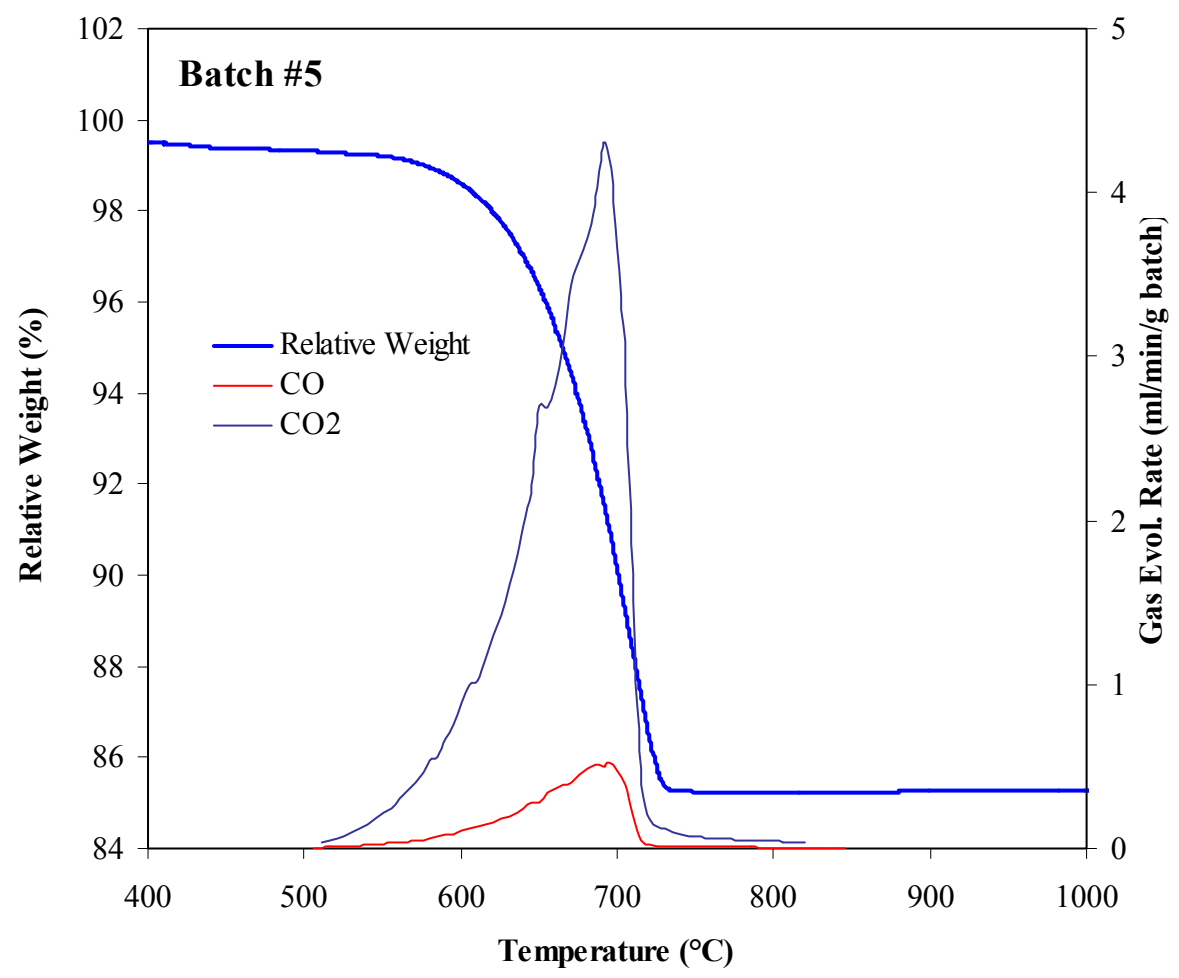

Figure 13. TGA and EGA of Batch \#5 (two parts feldspar and one part limestone)

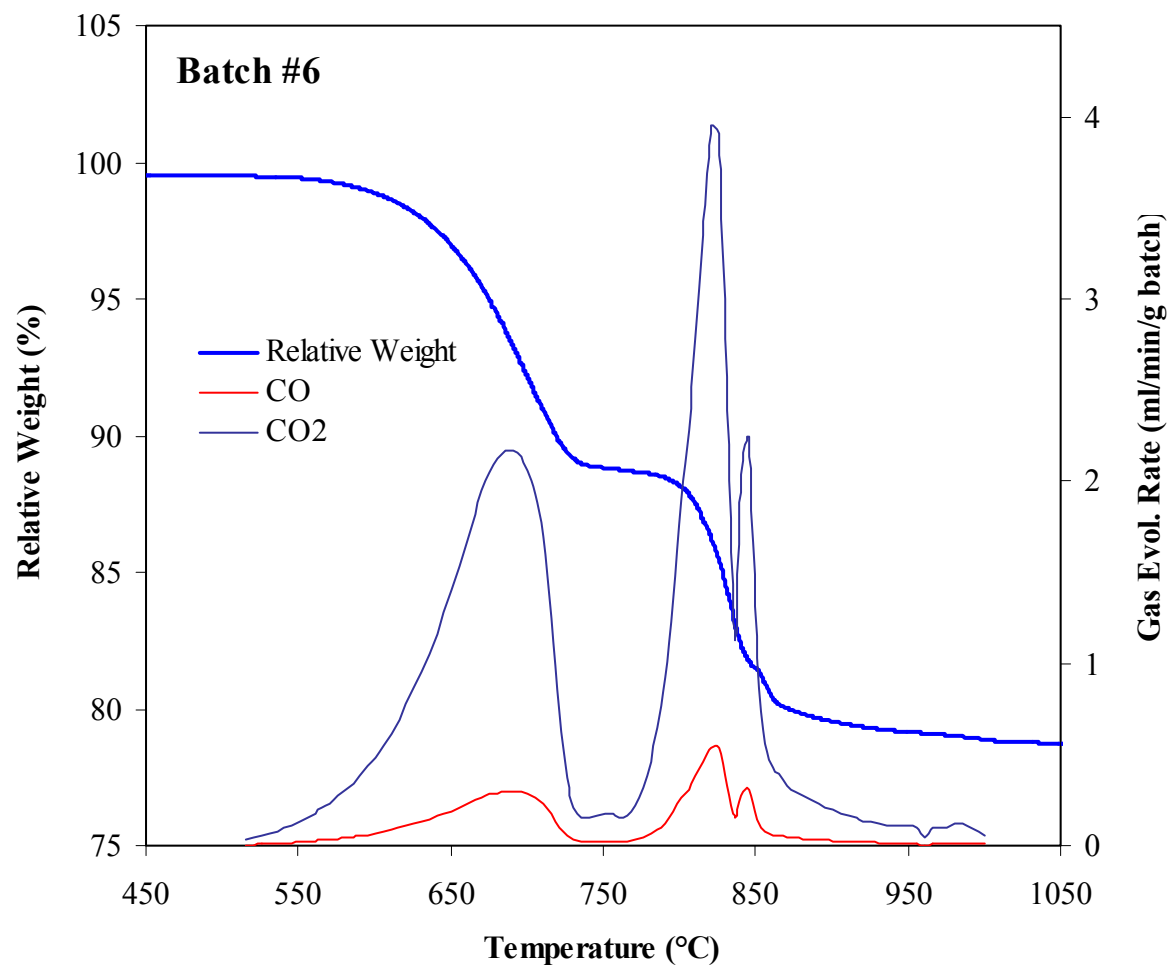

Figure 14. TGA and EGA of Batch \#6 (two parts sand, one part soda ash, and one part limestone) 


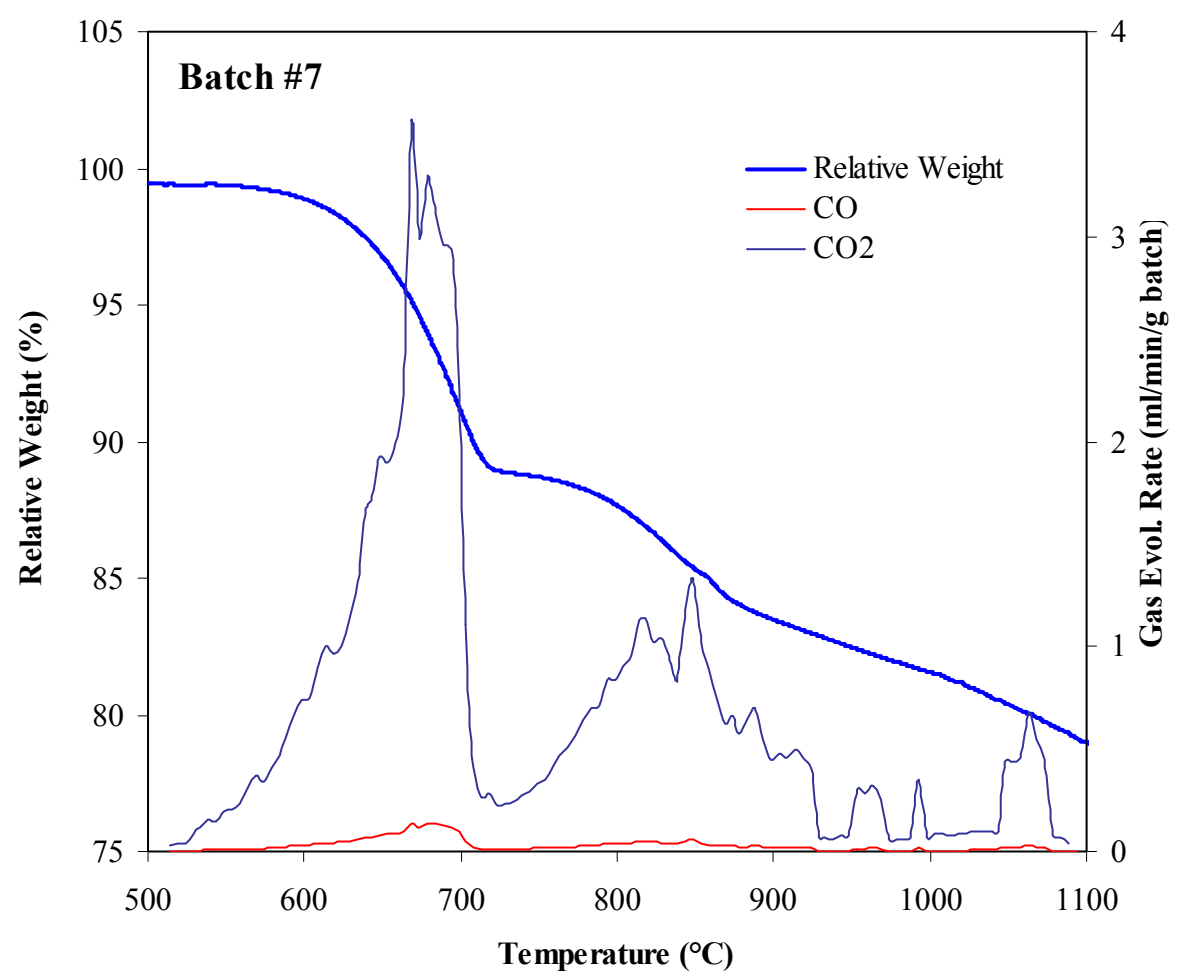

Figure 15. TGA and EGA of Batch \#7 (two parts feldspar, one part soda ash, and one part limestone)

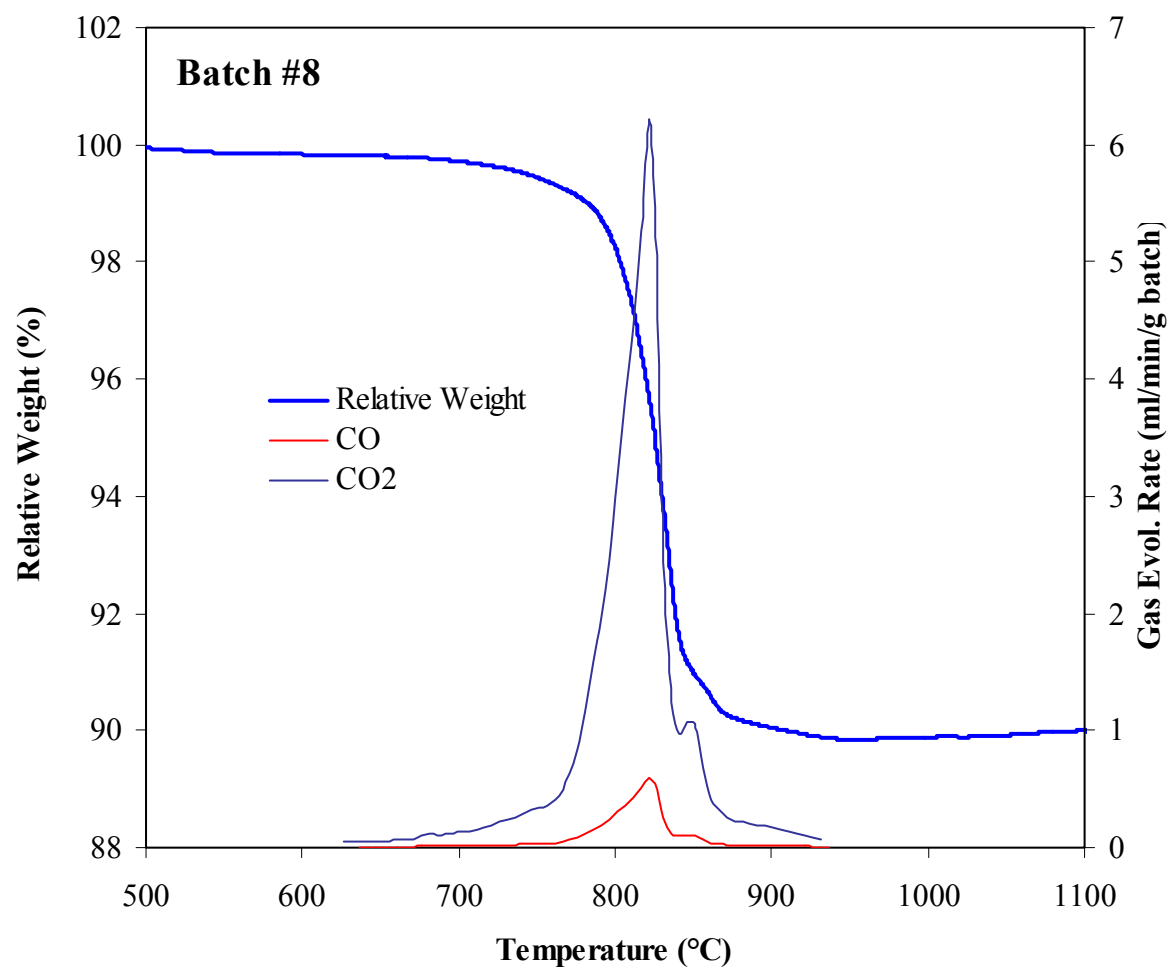

Figure 16. TGA and EGA of Batch \#8 (two parts sand, one part soda ash, and one part burnt lime) 


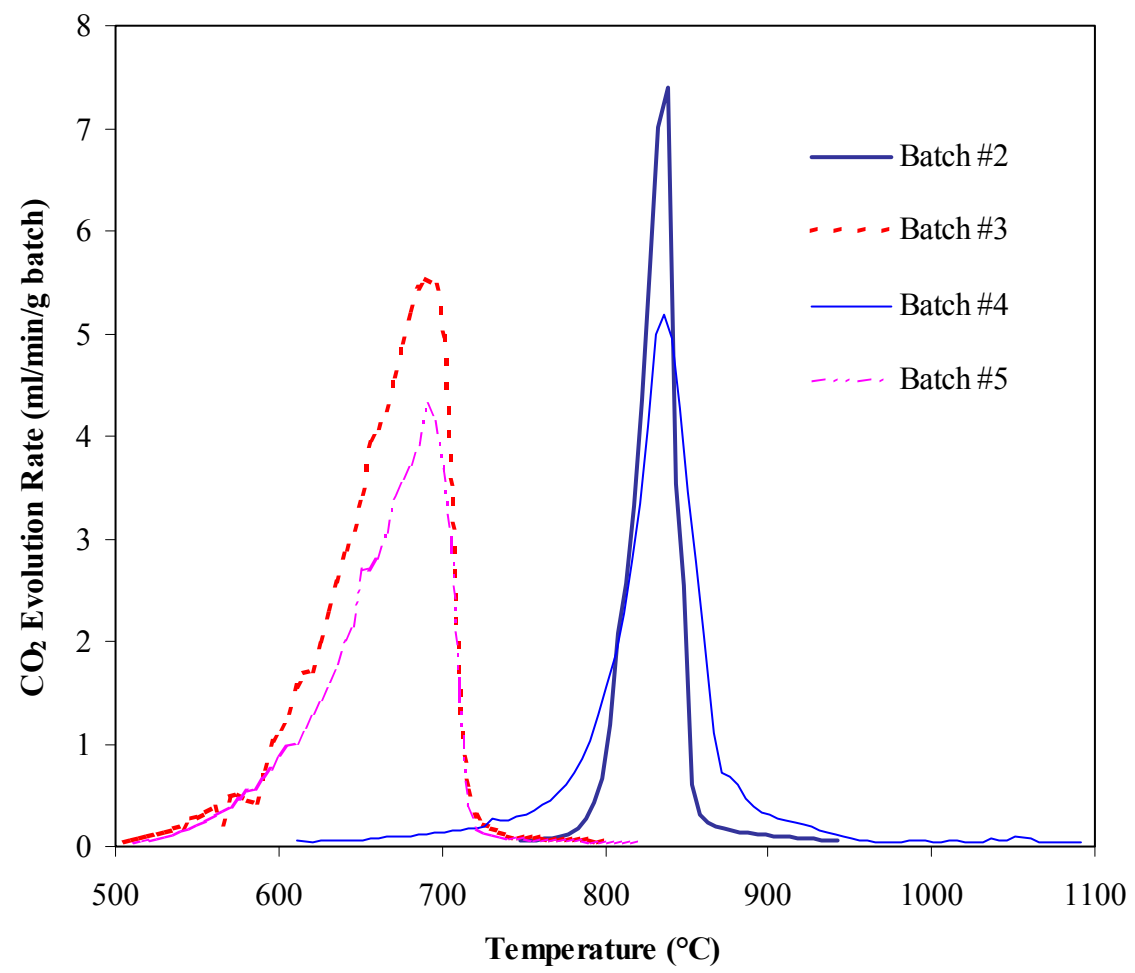

Figure 17. Comparison of $\mathrm{CO}_{2}$ Evolution Rate in Two-Component Batches (\#2 - \#5)

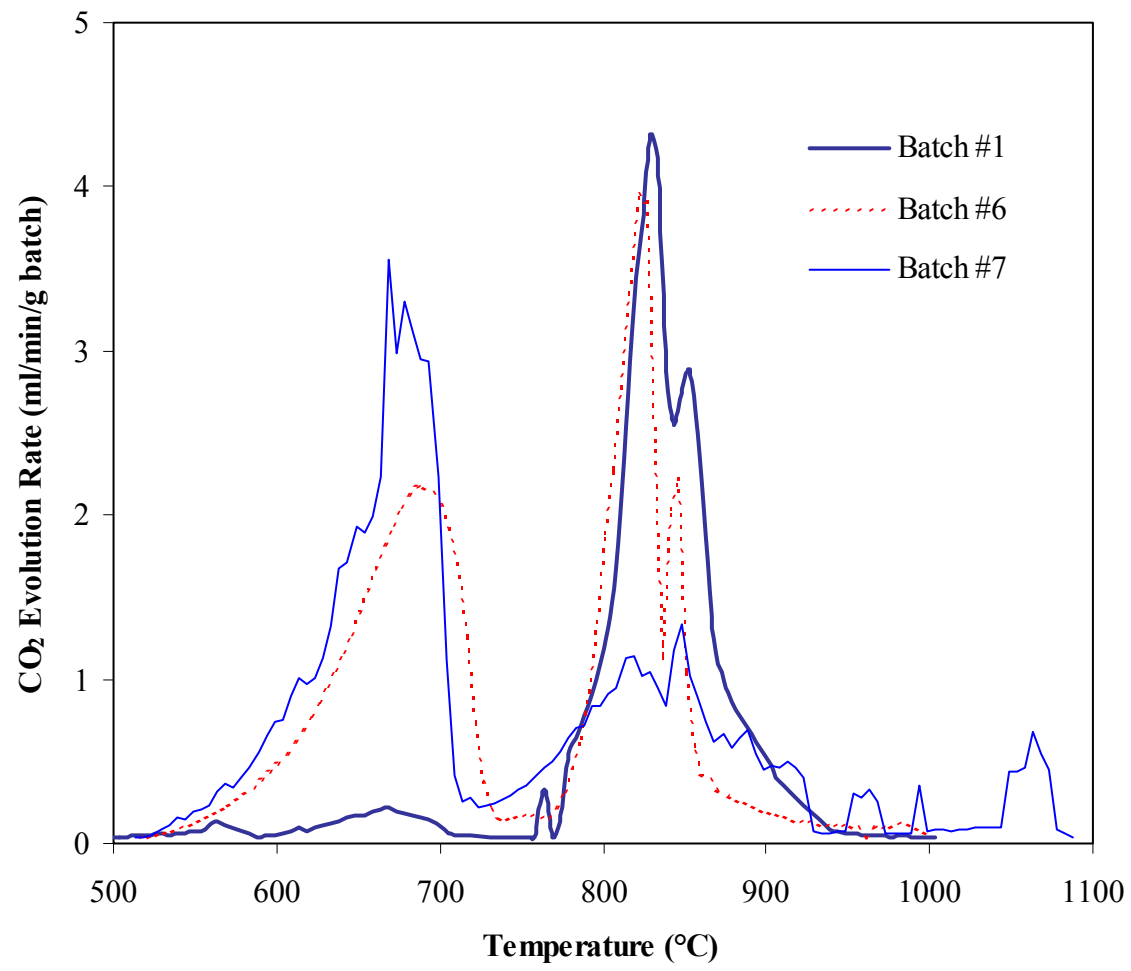

Figure 18. Comparison of $\mathrm{CO}_{2}$ Evolution Rate in Multi-Component Batches (\#1, \#6, and \#7) 


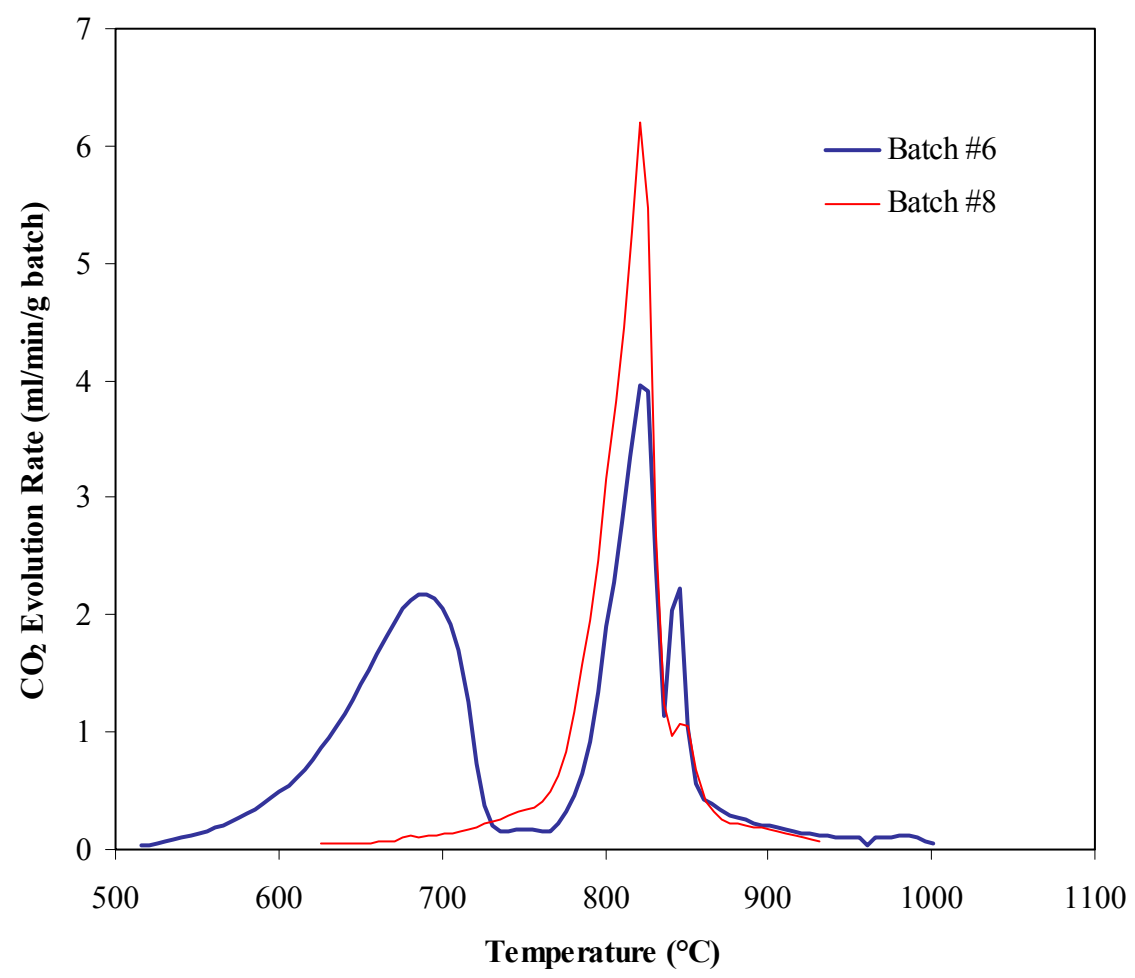

Figure 19. Comparison of $\mathrm{CO}_{2}$ Evolution Rate in Sand-Soda Ash Batches with Limestone (\#6) and Burnt Lime (\#8) as a Source of Alkaline Earth Oxides ( $\mathrm{CaO}$ and $\mathrm{MgO})$ 


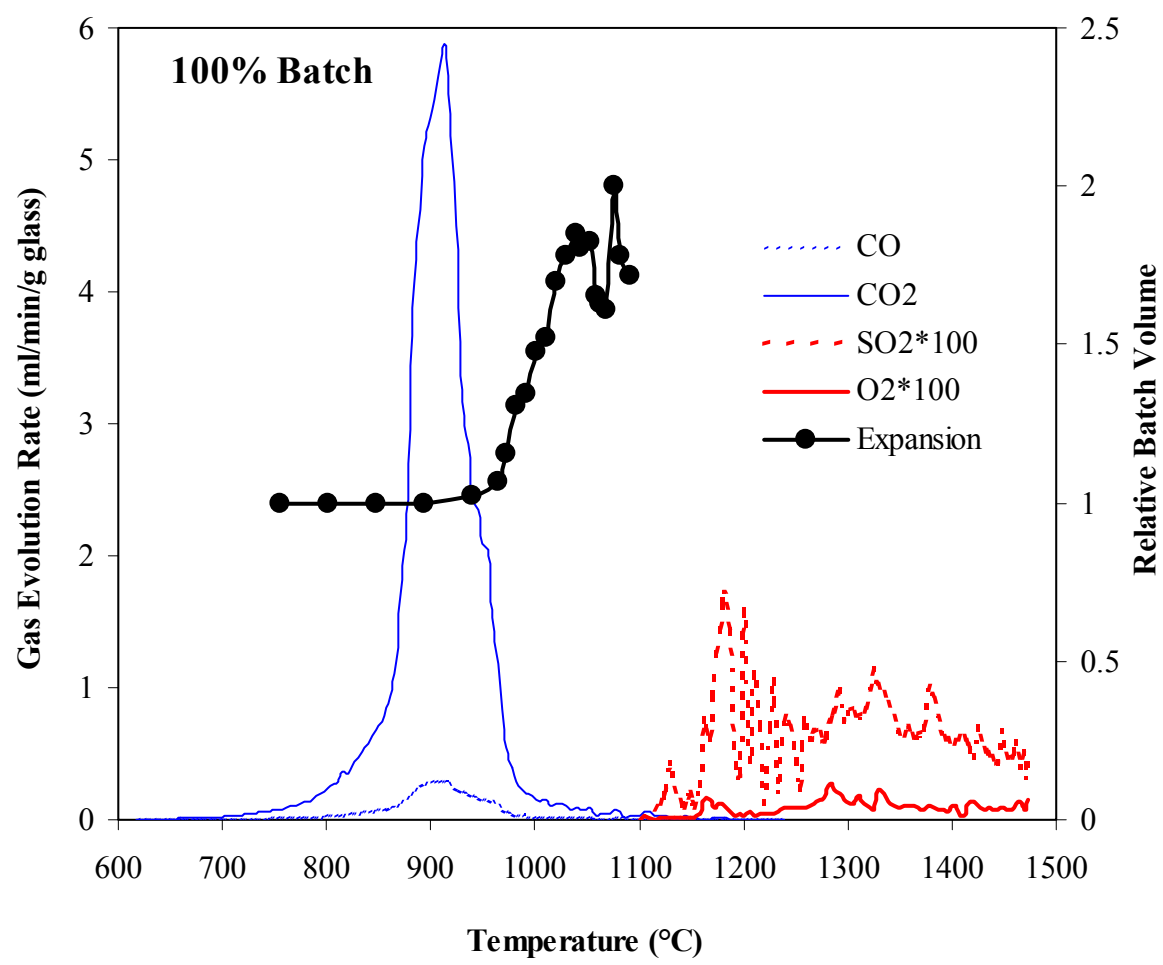

Figure 20. Gas Evolution Rate and Batch Expansion of 100\% Batch as a Function of Temperature

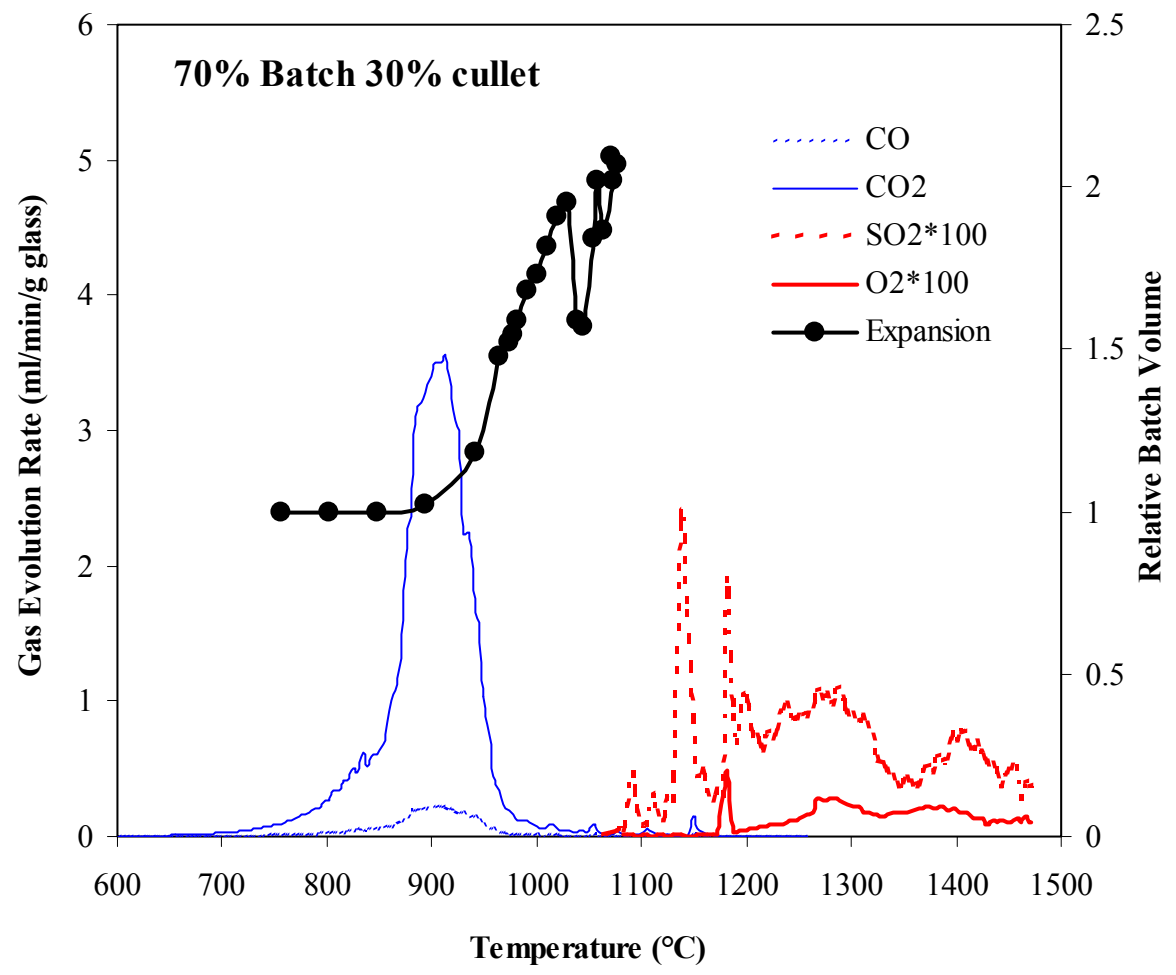

Figure 21. Gas Evolution Rate and Batch Expansion of 70\% Batch - 30\% Cullet as a Function of Temperature 


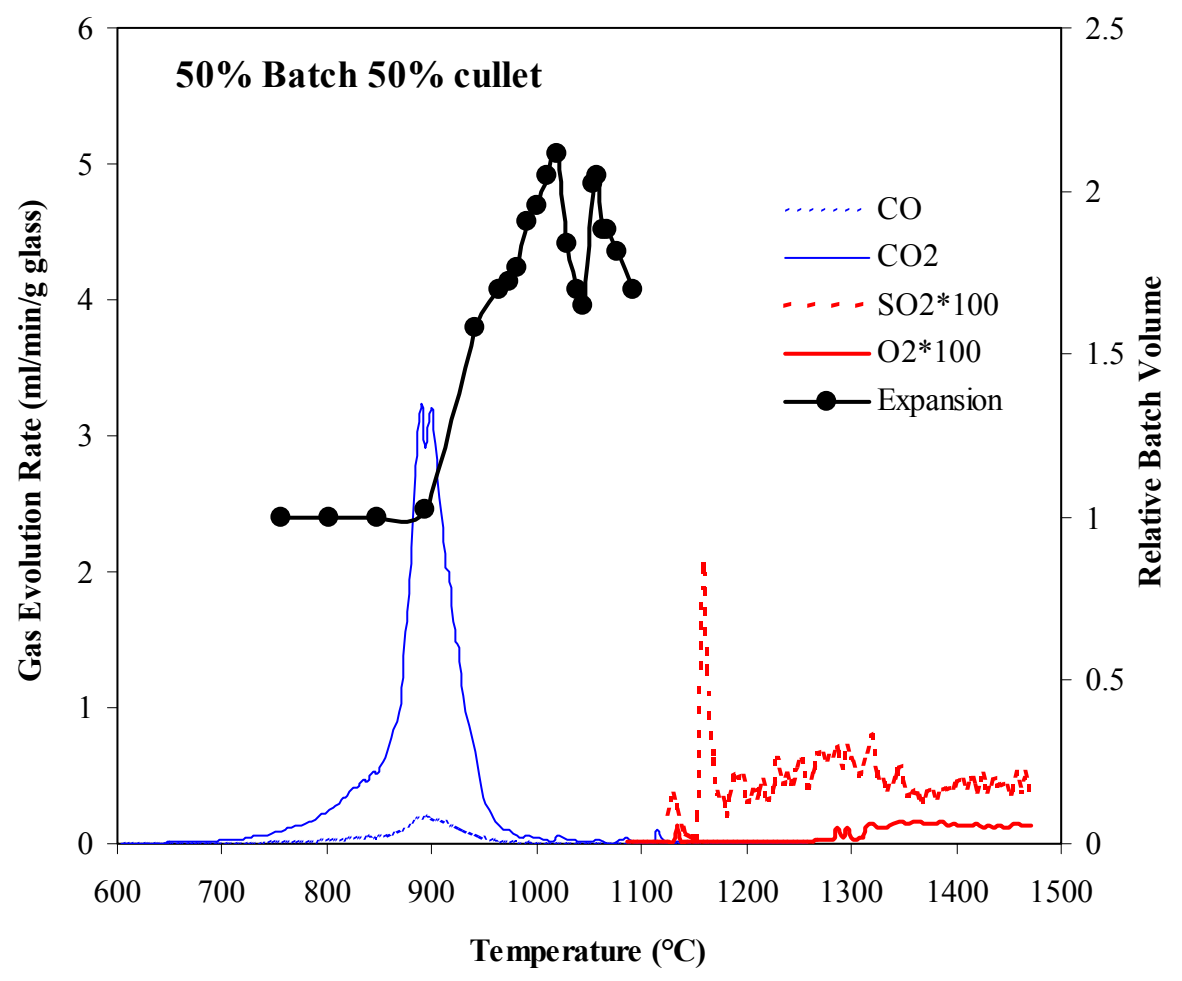

Figure 22. Gas Evolution Rate and Batch Expansion of 50\% Batch - 50\% Cullet as a Function of Temperature

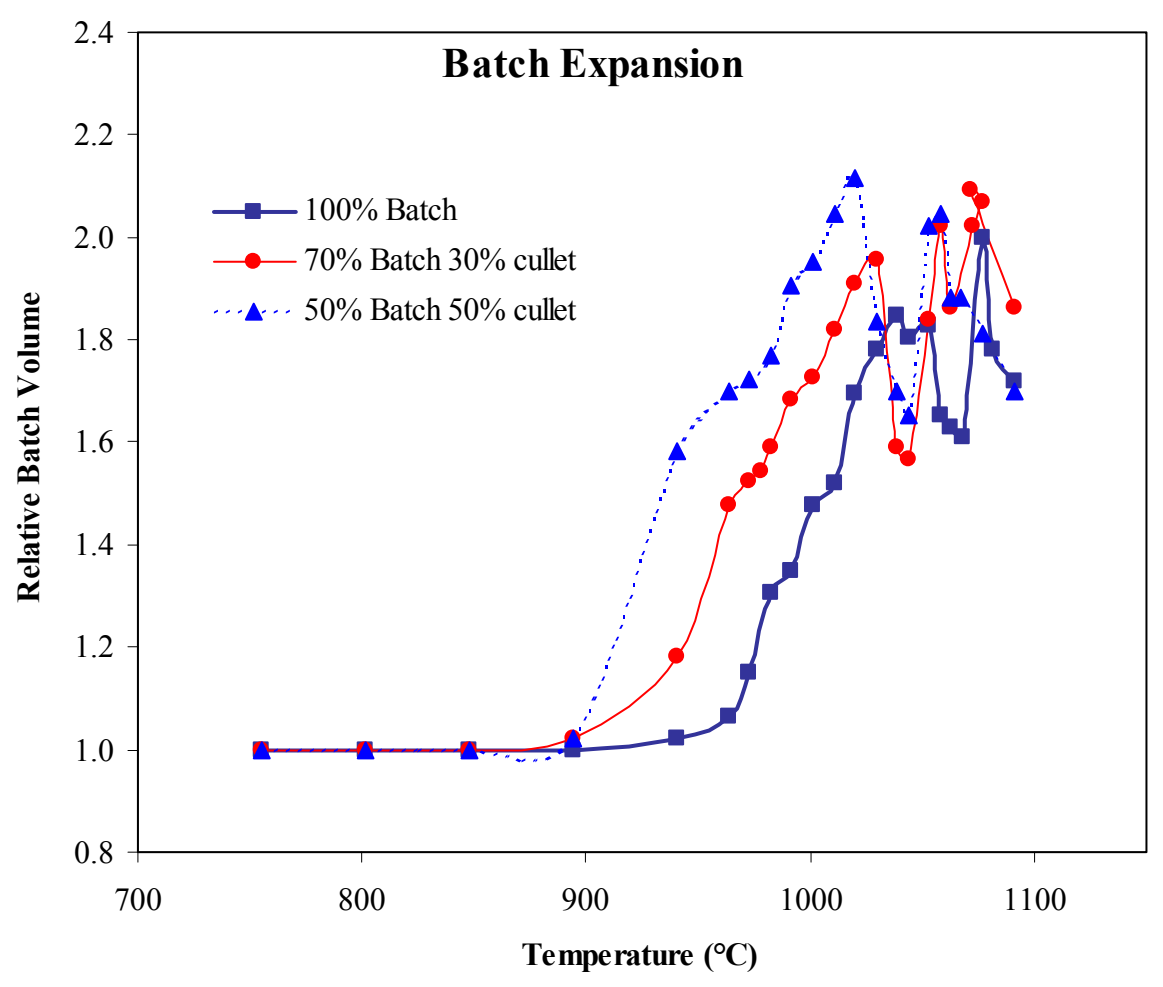

Figure 23. Comparison of Batch Expansion in Batches with Different Cullet Contents 


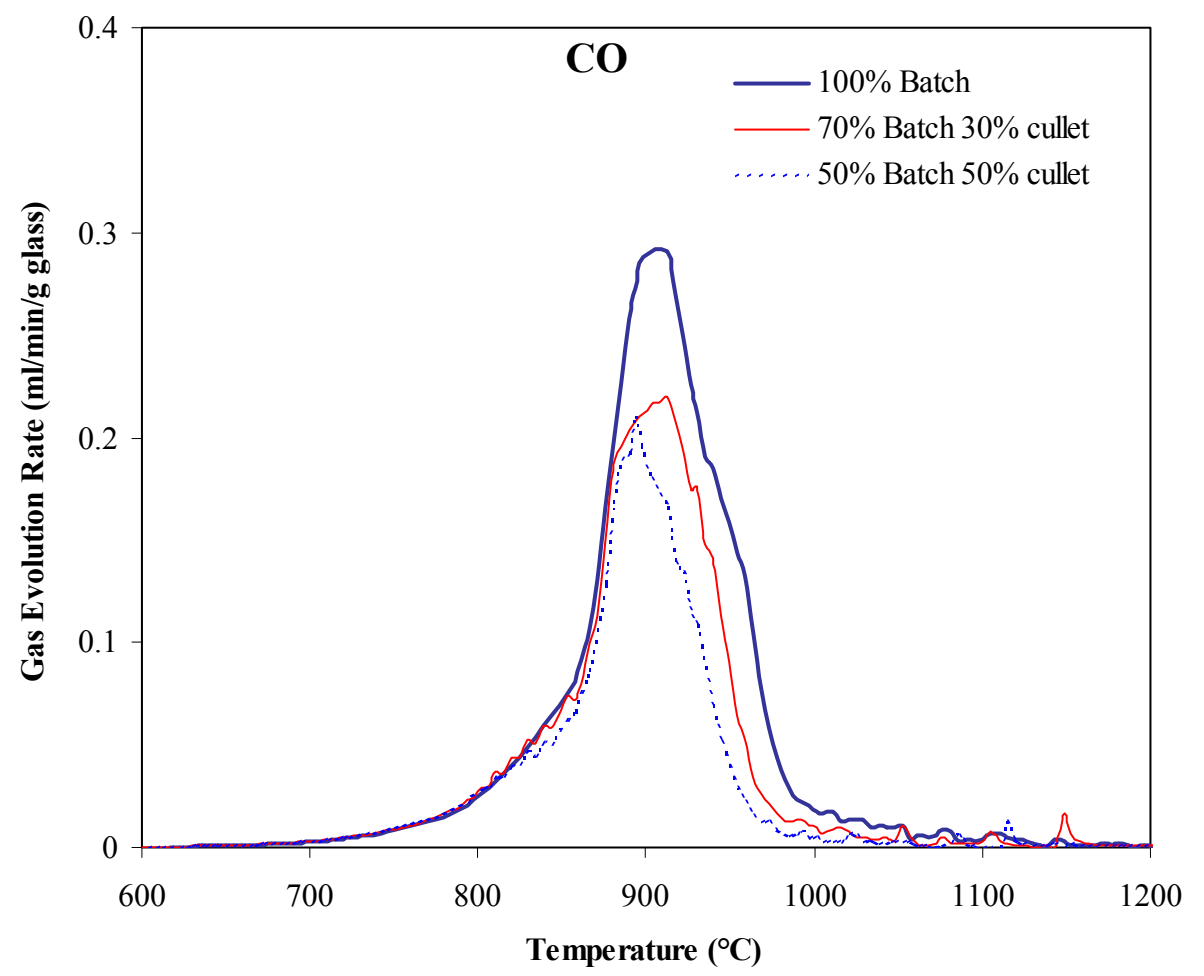

Figure 24. Comparison of CO Evolution Rates in Batches with Different Cullet Contents

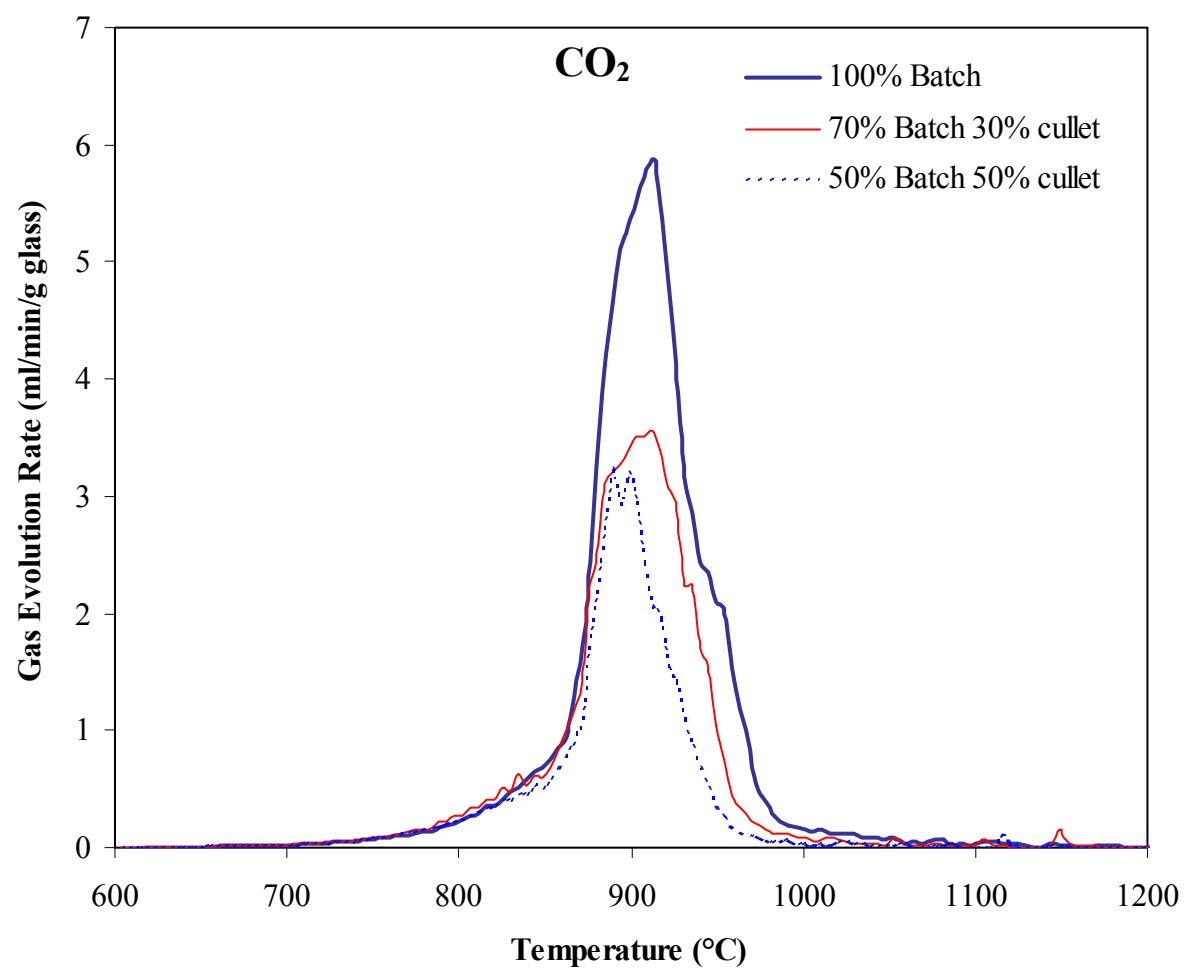

Figure 25. Comparison of $\mathrm{CO}_{2}$ Evolution Rates in Batches with Different Cullet Contents 


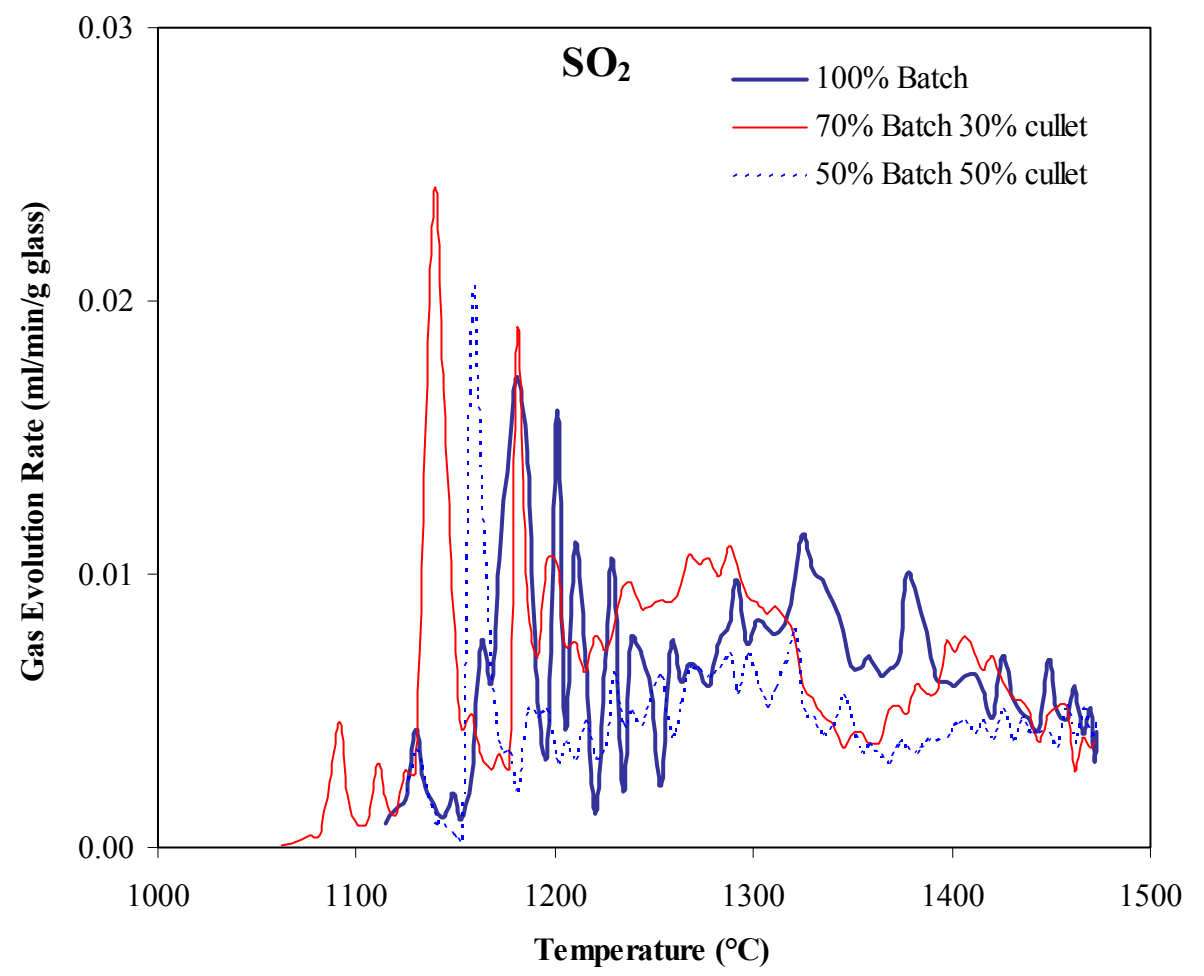

Figure 26. Comparison of $\mathrm{SO}_{2}$ Evolution Rates in Batches with Different Cullet Contents

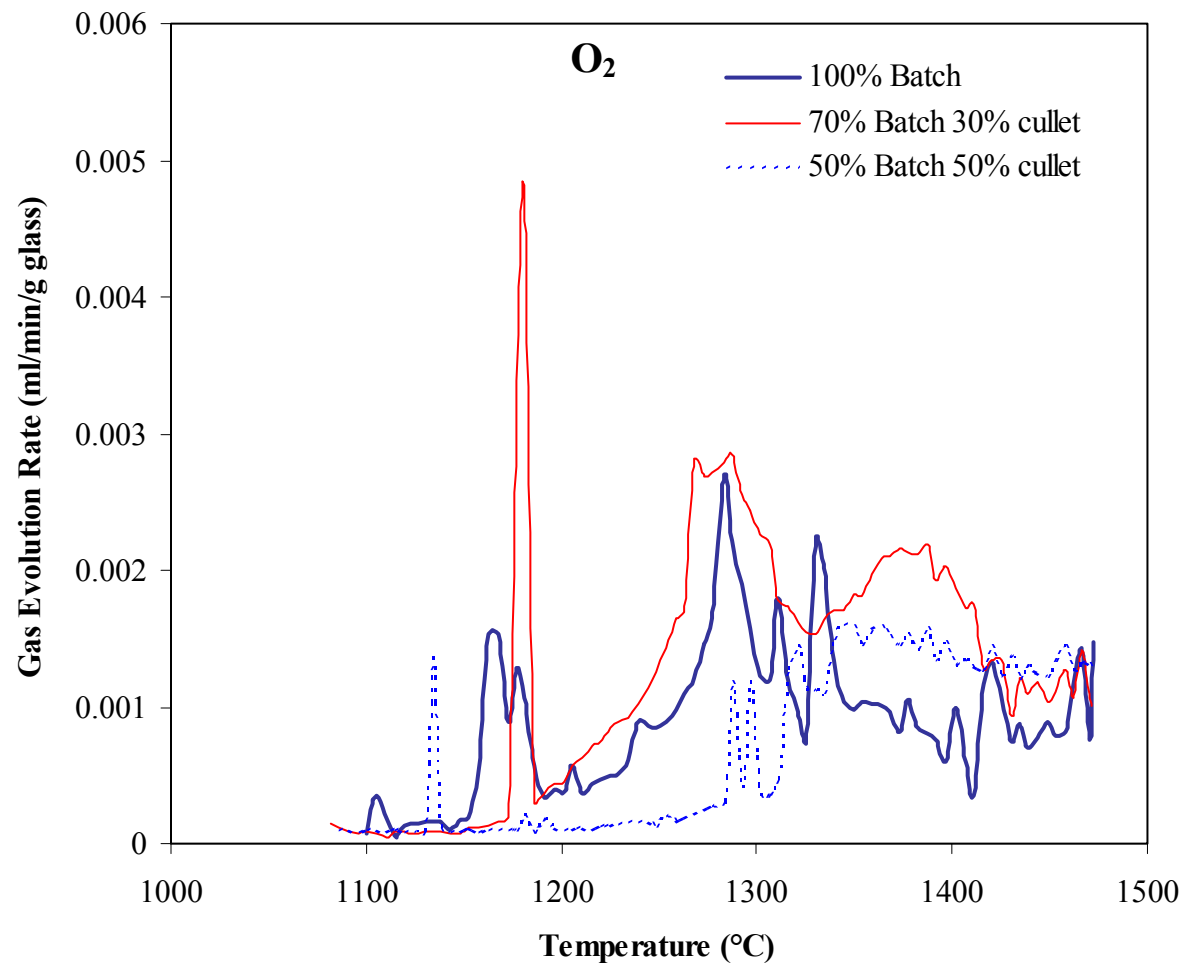

Figure 27. Comparison of $\mathrm{O}_{2}$ Evolution Rates in Batches with Different Cullet Contents 


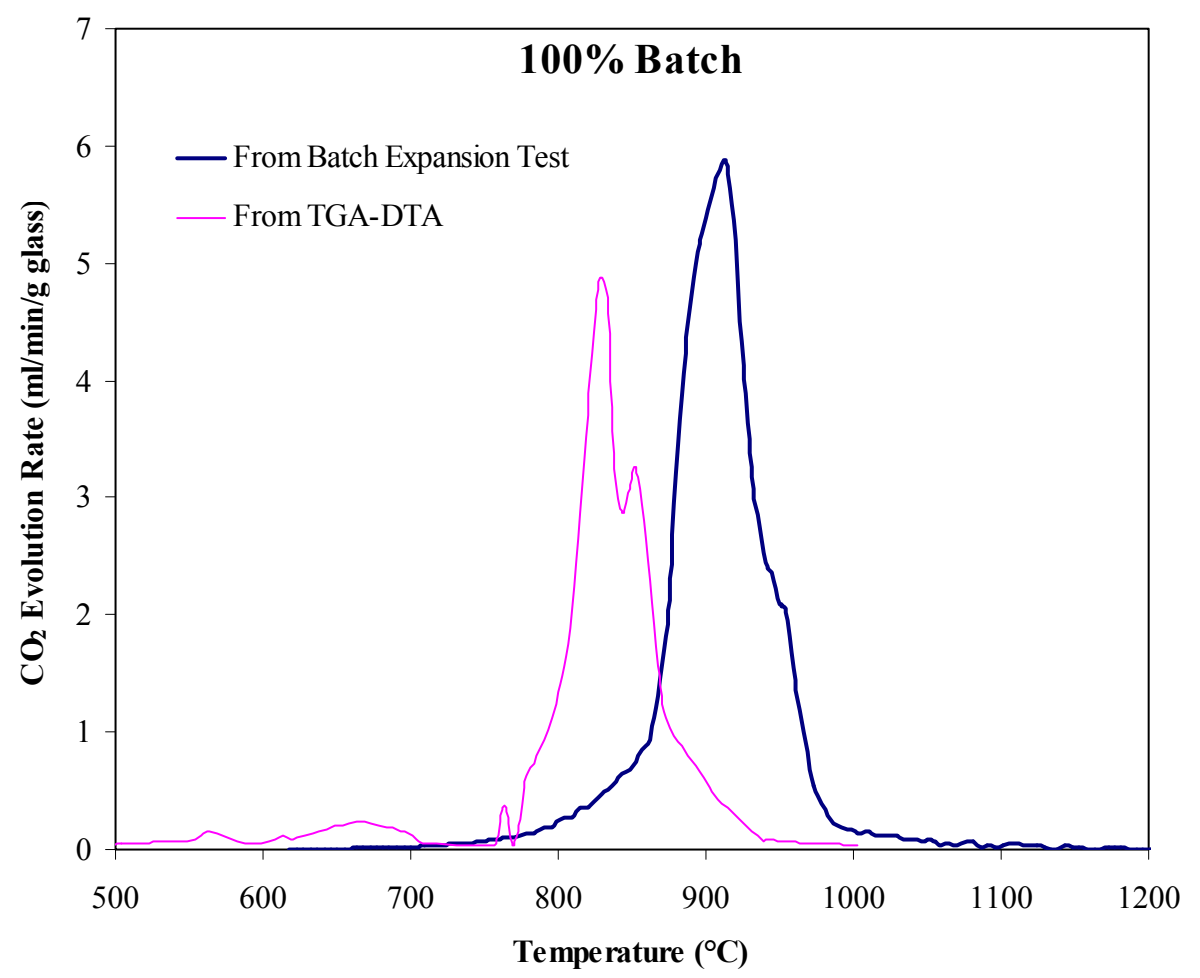

Figure 28. Comparison of $\mathrm{CO}_{2}$ Evolution Rate in $100 \%$ Batches Measured in TGA-DTA and Quartz-Crucible Batch Expansion Tests 


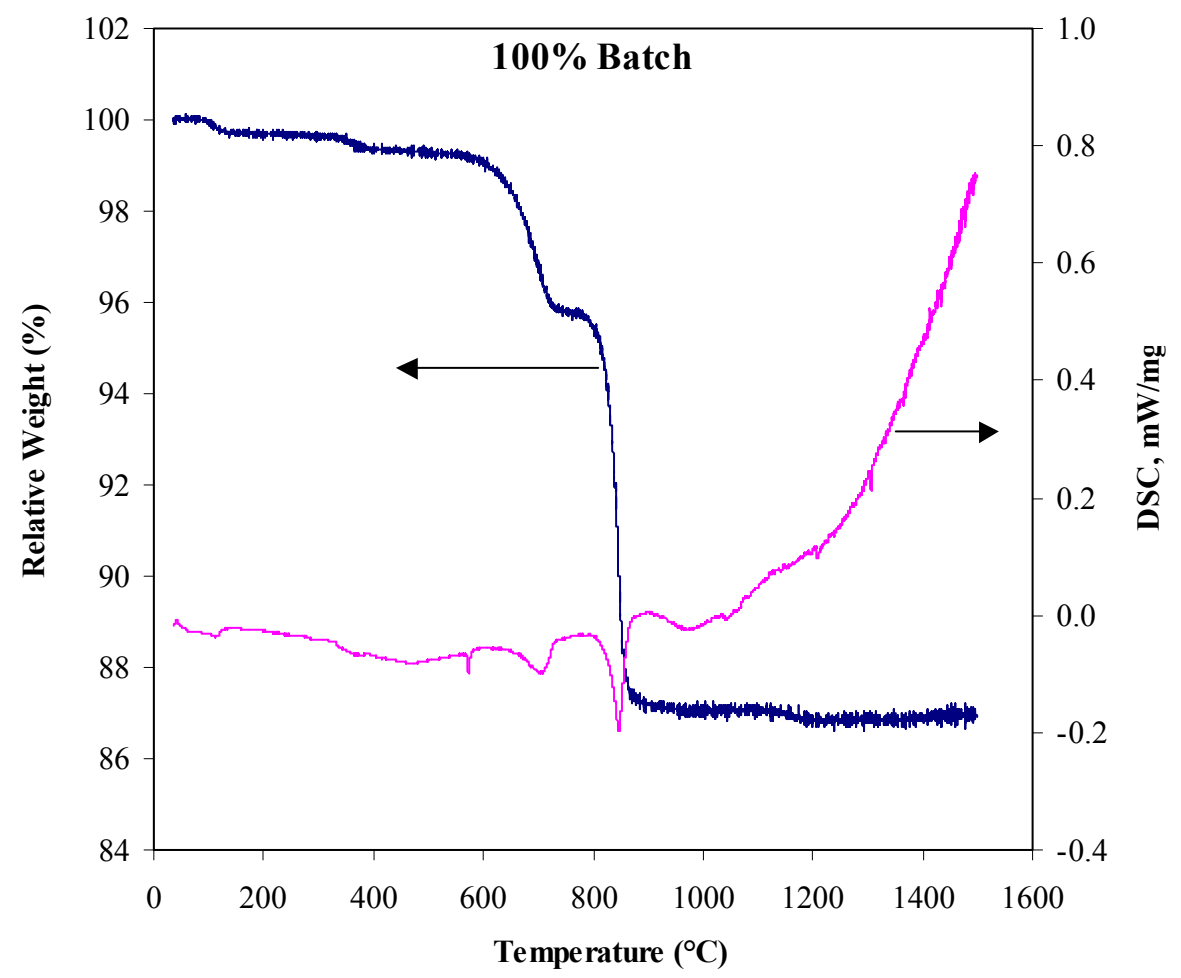

Figure 29. Simultaneous DTA-DSC Results on 100\% Batch

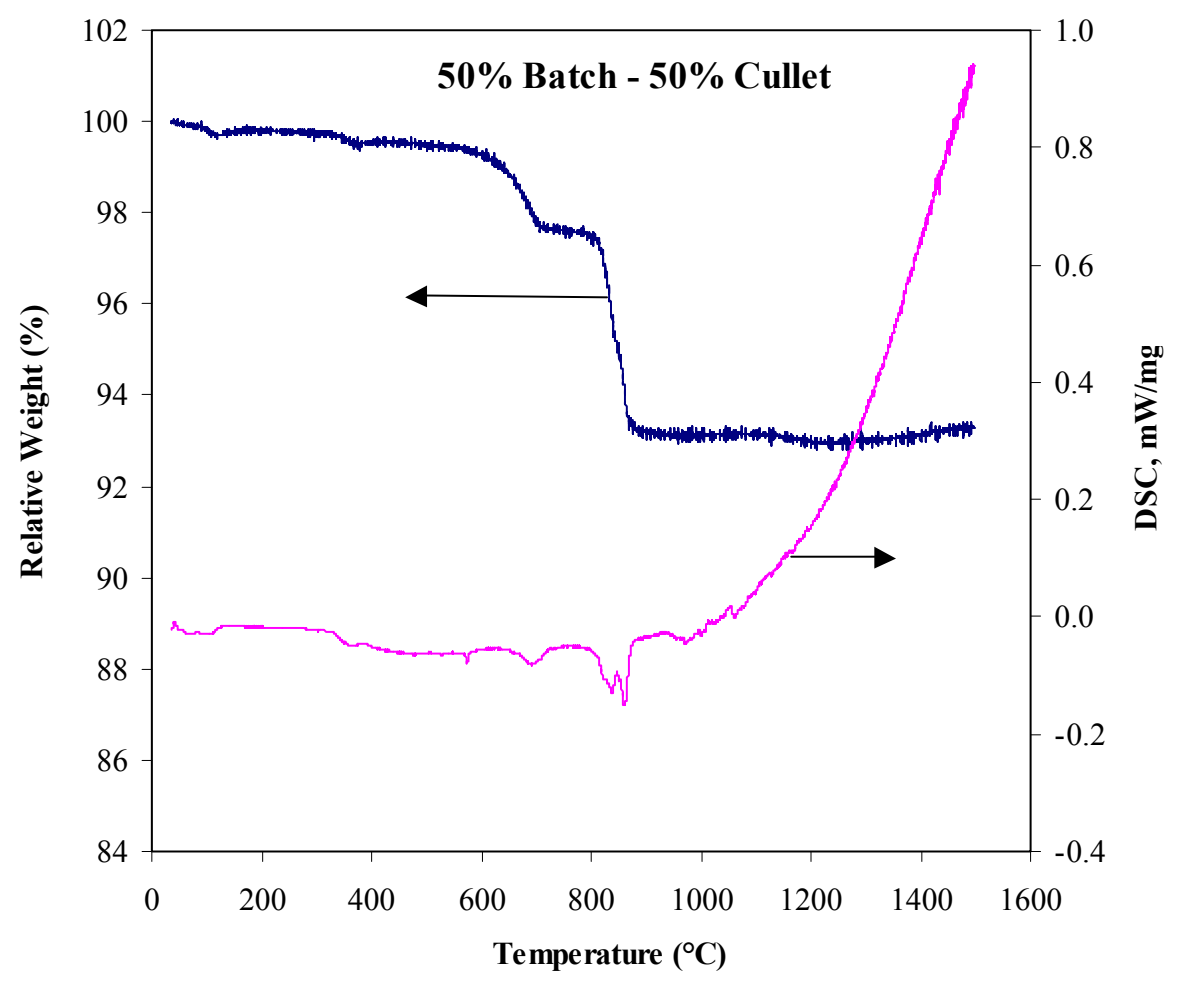

Figure 30. Simultaneous DTA-DSC Results on 50\% Batch - 50\% Cullet 


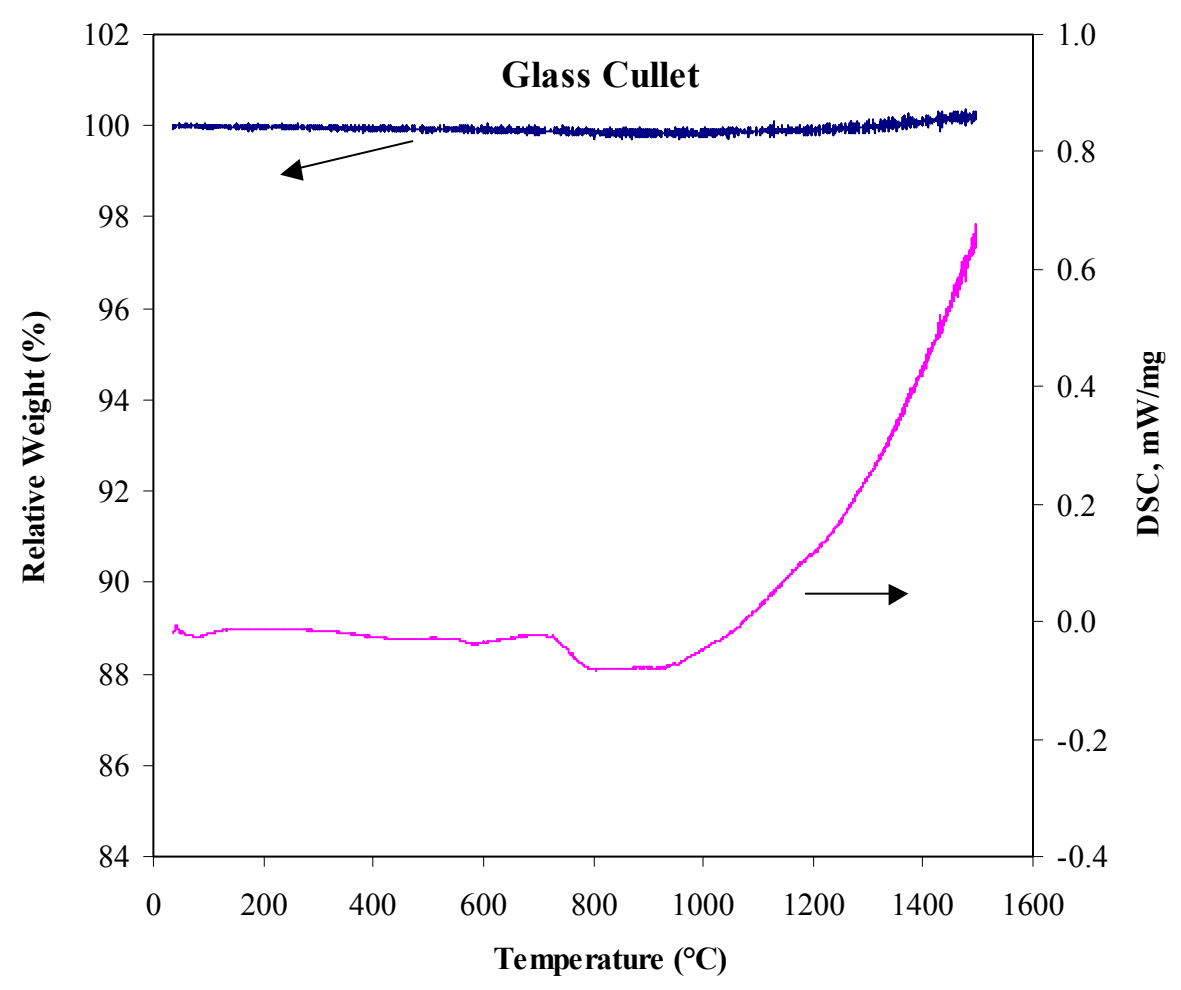

Figure 31. Simultaneous DTA-DSC Results on $100 \%$ Cullet

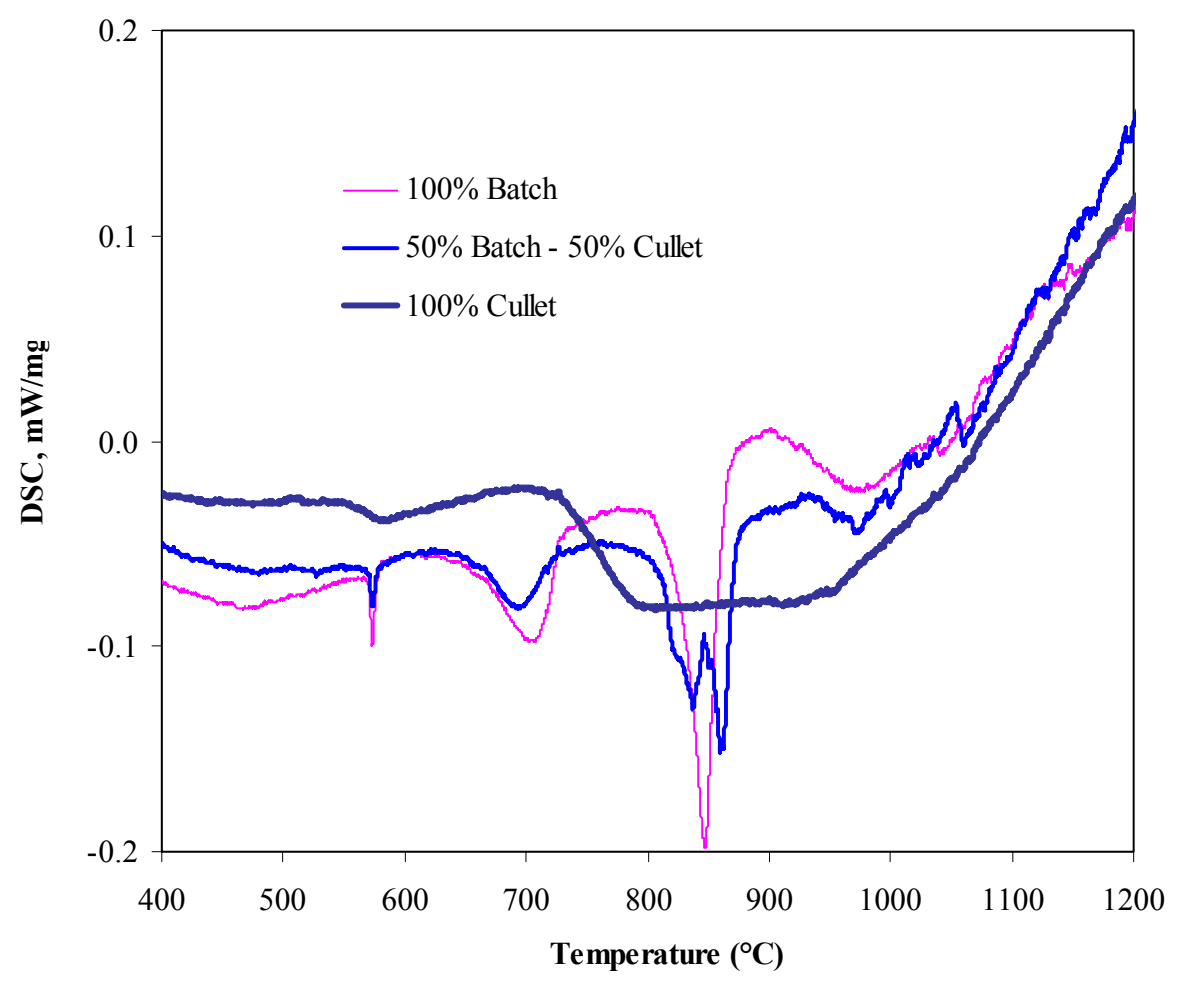

Figure 32. Comparison of DSC Curves in 100\% Batch, 50\% Batch - 50\% Cullet, and 100\% Cullet 


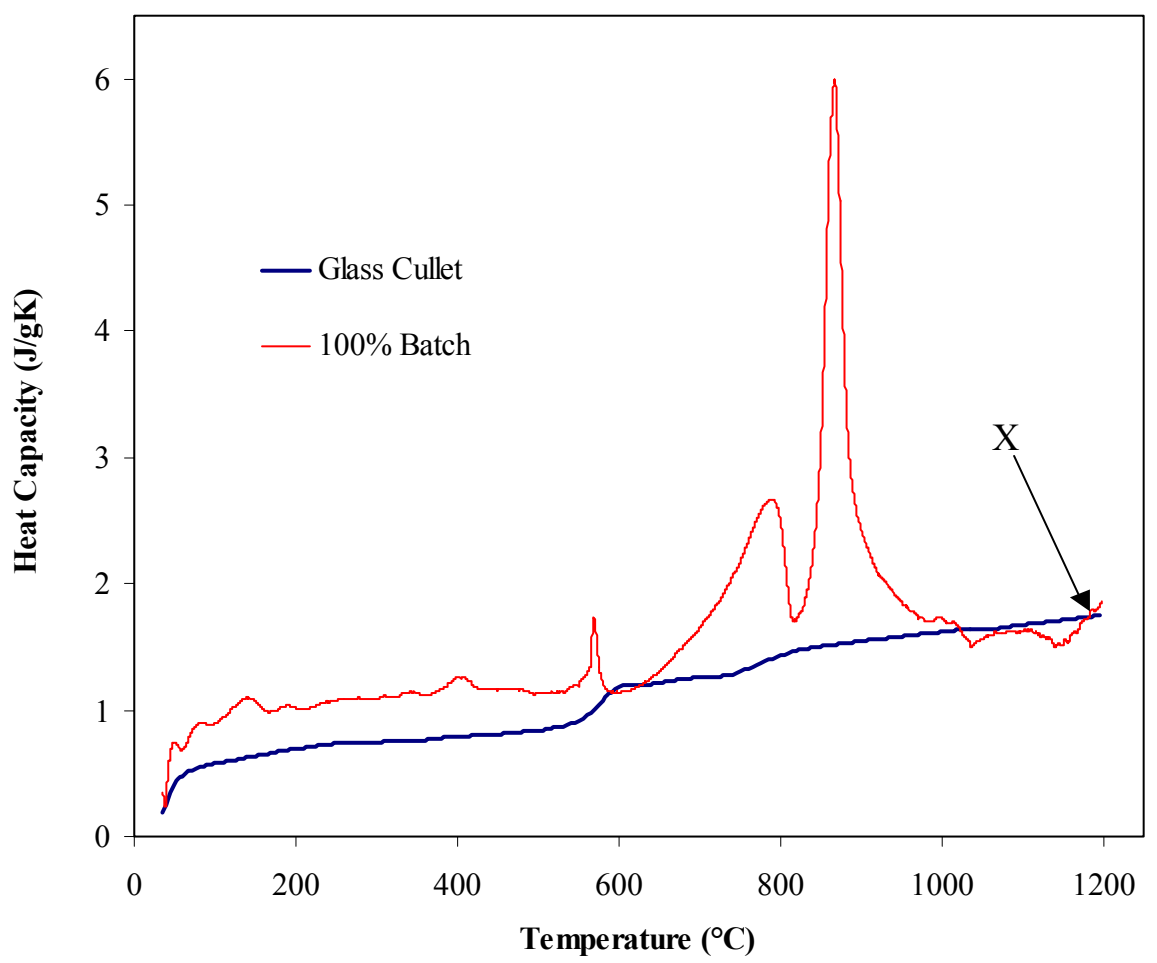

Figure 33. Heat Capacity as a Function of Temperature Measured by DSC

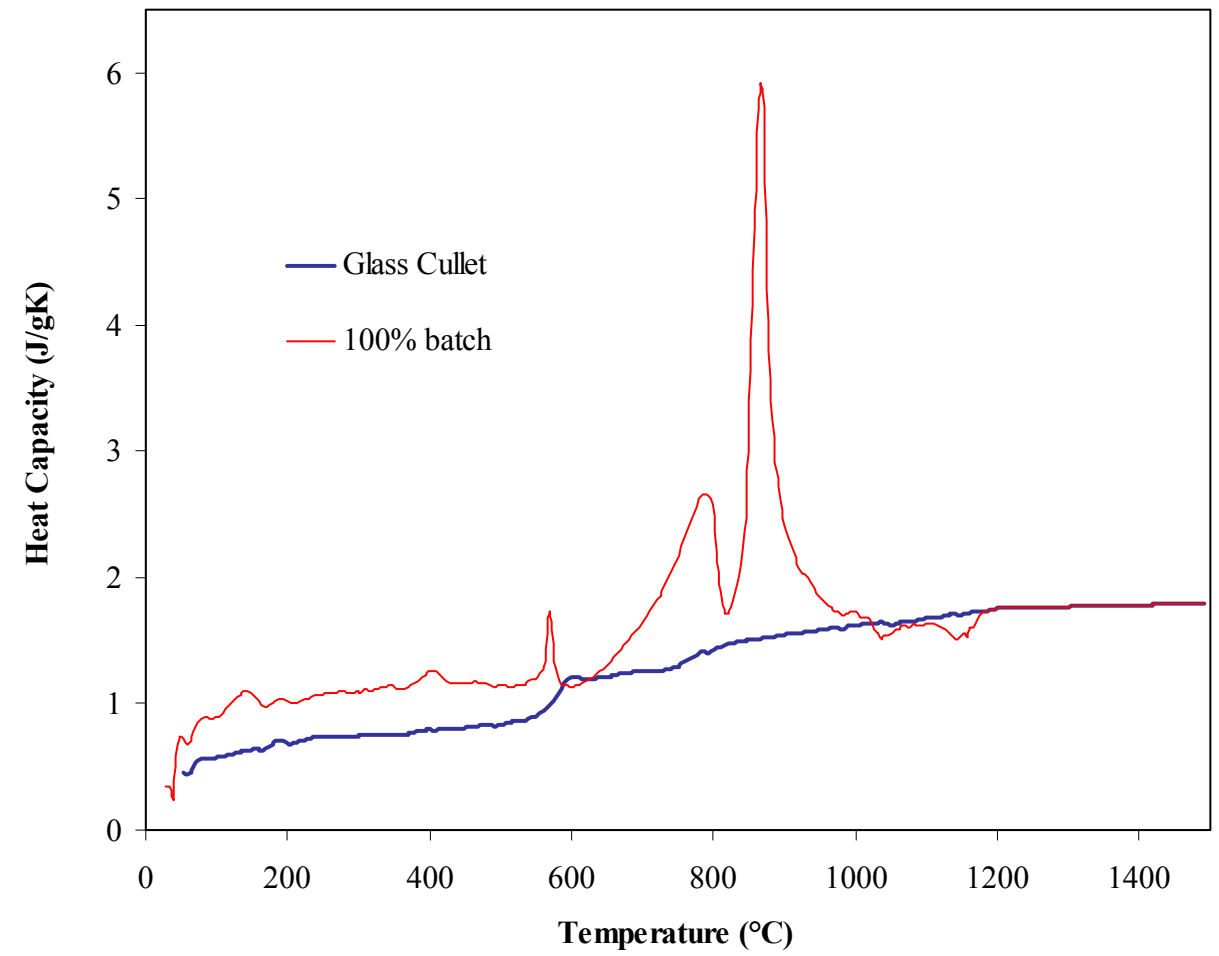

Figure 34. Heat Capacity Data Extrapolated to $1500^{\circ} \mathrm{C}$ Based on the Data for the Cullet from 1100 and $1200^{\circ} \mathrm{C}$ 


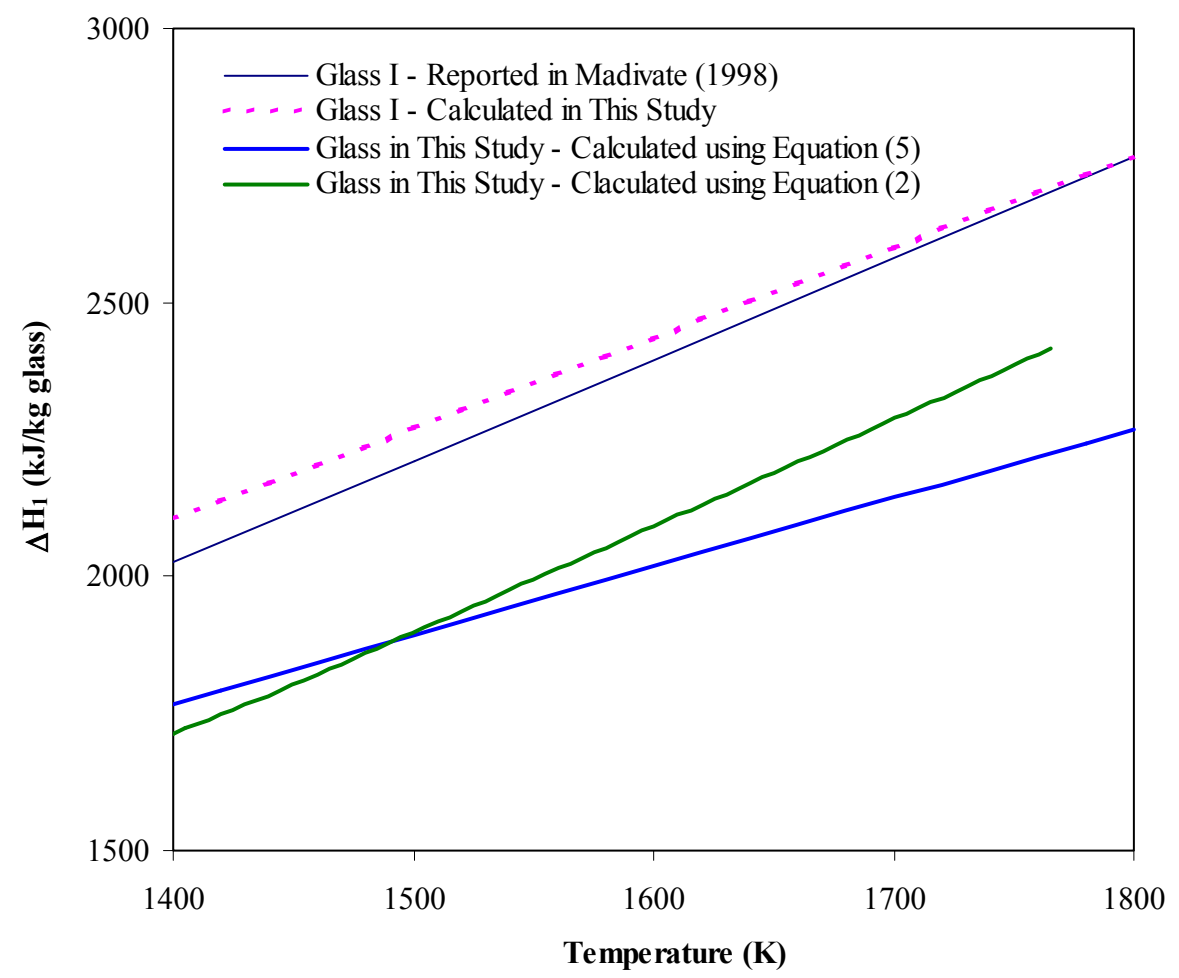

Figure 35. $\Delta H_{1}$ as a Function of Temperature for Clear Flat Glass (Glass I) Reported in Madivate (1998) and the Glass Used in this Study

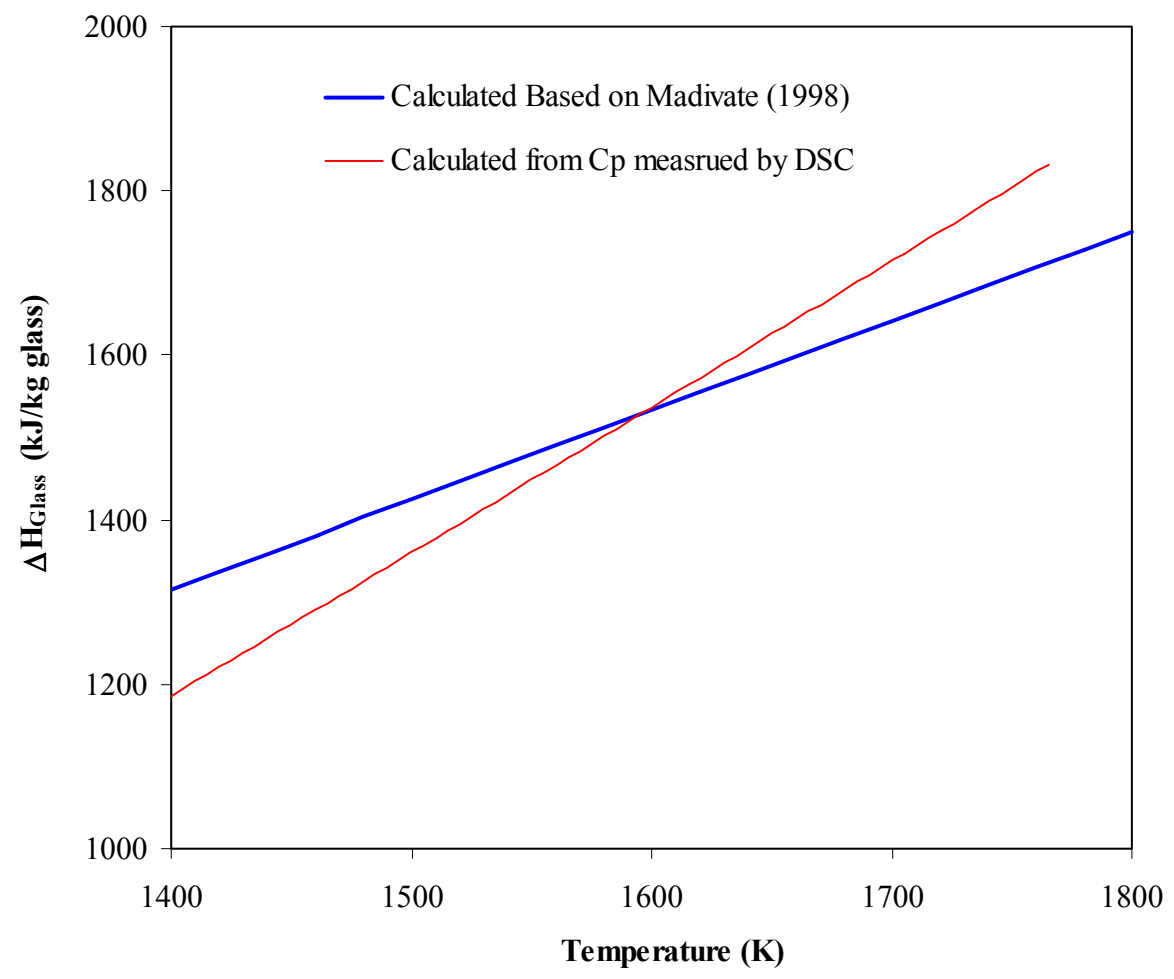

Figure 36. Comparison of $\Delta H_{\text {Glass }}$ of the Glass Used in this Study Calculated Based on Madivate (1998) and Calculated from $C p(T)$ Obtained from DSC Measurement 